\title{
Continuous monitoring of Hawaiian volcanoes with thermal cameras
}

\author{
Matthew R Patrick*, Tim Orr, Loren Antolik, Lopaka Lee and Kevan Kamibayashi
}

\begin{abstract}
Continuously operating thermal cameras are becoming more common around the world for volcano monitoring, and offer distinct advantages over conventional visual webcams for observing volcanic activity. Thermal cameras can sometimes "see" through volcanic fume that obscures views to visual webcams and the naked eye, and often provide a much clearer view of the extent of high temperature areas and activity levels. We describe a thermal camera network recently installed by the Hawaiian Volcano Observatory to monitor Kïlauea's summit and east rift zone eruptions (at Halema'uma'u and Pu'u 'Ō'o craters, respectively) and to keep watch on Mauna Loa's summit caldera. The cameras are long-wave, temperature-calibrated models protected in custom enclosures, and often positioned on crater rims close to active vents. Images are transmitted back to the observatory in real-time, and numerous Matlab scripts manage the data and provide automated analyses and alarms. The cameras have greatly improved HVO's observations of surface eruptive activity, which includes highly dynamic lava lake activity at Halema'uma'u, major disruptions to Pu'u 'Ö'ō crater and several fissure eruptions.
\end{abstract}

Keywords: Webcams; infrared; Kilauea; Mauna Loa; temperature

\section{Introduction}

Webcams are now a standard and essential component of effective volcano monitoring (Kirianov et al. 2002; Poland et al. 2008a; Hoblitt et al. 2008; Moran et al. 2008; Behncke et al. 2009; Ripepe et al. 2009; Patrick et al. 2010; Arason et al. 2011; Schaefer 2012; Orr et al. 2013a). Visible-wavelength $(0.4-0.7 \mu \mathrm{m})$ webcams, however, have numerous limitations. In many cases, volcanic vents are obscured by thick volcanic fume (a term we use to refer to volcanic gas and particles, such as aerosols), severely impairing or blocking observations of activity. In other cases, it is difficult to identify the extent of hot volcanic material (such as lava or fumarolic surfaces), because these surfaces may not always be incandescent, or their incandescence may not be strong enough to stand out from sunlit surfaces. Low-light, or near-infrared $(\sim 1 \mu \mathrm{m})$, cameras offer an improvement upon visiblewavelength cameras in these regards (Sentman et al. 2010), but still suffer from these limitations to a large degree.

\footnotetext{
*Correspondence: mpatrick@usgs.gov

Hawaiian Volcano Observatory-US Geological Survey, PO Box 51, Hawai'i National Park, HI, 96718, USA
}

Thermal (i.e. long-wave infrared, 7.5-13 $\mu \mathrm{m}$ ) cameras provide a valuable complement to visual cameras by mitigating the aforementioned problems. Often (but not always), thermal cameras can "see" through thick volcanic fume, providing a view of active vents that would not otherwise be possible. Perhaps most importantly, they offer an unambiguous depiction of the extent of hot, warm and cool areas, making discrimination between active, recently active, and inactive surfaces very straightforward. Unlike visible or near-infrared cameras, their capacity for observation is not significantly affected by diurnal changes in sunlight, enhancing the clarity of long-term observation.

Beyond tracking ongoing eruptions, thermal cameras can also monitor changes that may presage eruptive activity. Patrick and Witzke (2011) describe selected examples of thermal precursors that were observed at volcanoes including Tokachi (Japan; Yokoyama 1964), Mt. St. Helens (USA; Kieffer et al. 1981), Stromboli (Italy; Bonaccorso et al. 2003) and Santa Ana (El Salvador; Hernández et al. 2007). In Hawaii i, hikers observed red glow and anomalous steaming coming from cracks in the summit caldera of Mauna Loa a few days before the 1984 eruption began (Lockwood et al. 1987). Some of these observations of 
thermal precursors may have been serendipitous, and continuously-operating thermal cameras offer a continuous tool for detection of such precursors.

Handheld thermal cameras have been used in numerous field campaigns at many volcanoes around the world, but far fewer fixed, continuously operating, thermal camera installations exist. In the last ten years, however, more of these continuous systems have been installed on a handful of volcanoes. Thermal cameras at the summit of Stromboli volcano were vital in tracking the onset and progress of the 2007 effusive eruption, which began with the opening of hot fissures that drained the uppermost magma column (Ripepe et al. 2009; Calvari et al. 2010). Delle Donne et al. (2006) used data from a fixed thermal camera on Stromboli to analyze almost 20,000 explosions, and integrated the observed dynamics with infrasound to create one of the longest-term characterizations of strombolian explosive behavior to date. Thermal cameras are one component in an extensive network closely monitoring Mt. Etna, where explosive activity can rapidly threaten air traffic around the city of Catania (Alparone et al. 2007; Bonaccorso et al. 2011). Thermal cameras were installed in 2006 to monitor the fumarole field at Vulcano, Italy, and have detected a decreasing trend in fumarole temperatures (Lodato et al. 2009). Chiodini et al. (2007) describes a thermal camera installed in 2004 at Campei Flegrei, Italy, that detected subtle offsets in thermal output of the fumarole field associated with two seismic swarms, which may have impacted the hydrothermal system. A thermal camera was installed at Turrialba volcano in 2010 by University of Costa Rica geologists to monitor gas emission from fissures that opened in June 2007 (M. Mora, written communication). During the 2010 eruption of Eyjafjallajökull, Iceland, a telecommunications company installed a thermal camera about $10 \mathrm{~km}$ from the volcano to monitor activity. Yokoo (2009) used a continuously operating thermal camera, installed in 2007, to monitor the explosive eruptions at Sakurajima volcano, Japan, during 2008 and study the thermal evolution of the ash plumes. Thermal cameras have provided insightful results during field campaigns at Erebus lava lake (Oppenheimer et al. 2009), and plans are underway to install a permanent fixed camera there (N. Peters, written communication). Spampinato et al. (2011) and Harris (2013) provide comprehensive summaries of the theory of radiative transfer, technical limitations and recent applications of thermal cameras, both fixed and handheld, at volcanoes around the world.

In this paper, we detail the installation and image acquisition setup of several fixed thermal cameras on Kilauea and Mauna Loa volcanoes in Hawai $i$. These cameras were installed during 2010-2012 in a variety of environments and monitored volcanic processes including lava lakes, intracrater vents, fissure eruptions, lava flows and fumarolic activity (Patrick et al. 2012a). In addition to details on the equipment and setup specifications, we provide detailed summaries and code for the numerous Matlab scripts that manage image acquisition, image processing, data management and alarming (see Additional files 1, 2, 3, 4, 5, 6, 7). Finally, we highlight recent results from our thermal camera network, mostly during highly dynamic activity on Kîlauea in 2011, to demonstrate the potential of this system for both monitoring and understanding volcanic processes.

\section{Background}

\section{Recent volcanic activity in Hawai'i}

At the time of camera installation (2010-2012), there were two ongoing eruptions on Kilauea Volcano (Figures 1 and 2). First, the summit eruption in Halema'uma'u Crater began in March 2008, with the opening of a new vent immediately below the visitor overlook (Wilson et al. 2008). By 2010, the "Overlook crater" had enlarged to about $150 \mathrm{~m}$ in width through episodic vent wall collapses (Orr et al. 2013a). Since February 2010, a continuously active lava lake has been present deep within the vent crater (Orr et al. 2013a). The measured level of the lava has varied between 22 and $210 \mathrm{~m}$ below the floor of Halema'uma'u Crater, and in 2013 was typically $30-50 \mathrm{~m}$ below. The lava lake experienced major fluctuations in height during 2011, with abrupt drops corresponding to eruptive activity on Kilauea's east rift zone. The largest of these occurred in March 2011, when the lava lake dropped about $140 \mathrm{~m}$ (and disappeared from the vent crater) following the Kamoamoa intrusion/eruption in the east rift zone (Orr et al. 2013b).

In addition to Kilauea's summit eruption, the long-lived east rift zone eruption at $\mathrm{Pu}^{\prime} \mathrm{u}{ }^{\prime} \mathrm{O}^{\prime}{ }^{\prime}$, which began in 1983 (Heliker and Mattox 2003), continued with episodes 5861 during 2010-2012 (Orr et al. 2013b). Episode 58 (Poland et al. 2008b; Patrick et al. 2011a; Patrick and Orr 2011), ended with the Kamoamoa intrusion and fissure eruption (episode 59) in early March 2011 (Orr et al. 2013b). Following the Kamoamoa eruption, lava refilled Pu'u 'Ō'ō's crater (episode 60) and eventually broke out from the lower west flank of $\mathrm{Pu}^{\prime} \mathrm{u}$ ' ${ }^{\prime}{ }^{\prime} \bar{o}$ cone in early August 2011. Lava refilled $\mathrm{Pu}^{\prime} u{ }^{\prime} \mathrm{O}^{\prime} \bar{o}$ once again (episode 61), and burst through the upper east flank in late September 2011. These "Peace Day" lava flows reached the ocean in December 2011 and remained active until late 2013.

Mauna Loa's most recent eruption was in 1984 (Lockwood et al. 1987), when flows stalled within $7 \mathrm{~km}$ of the outskirts of the city of Hilo (pop. 43,000). A period of pronounced summit inflation and deep longperiod earthquakes in 2002-2004 suggested reawakening of the volcano but did not culminate in an eruption (Miklius and Cervelli 2003; Miklius et al. 2005; Amelung 

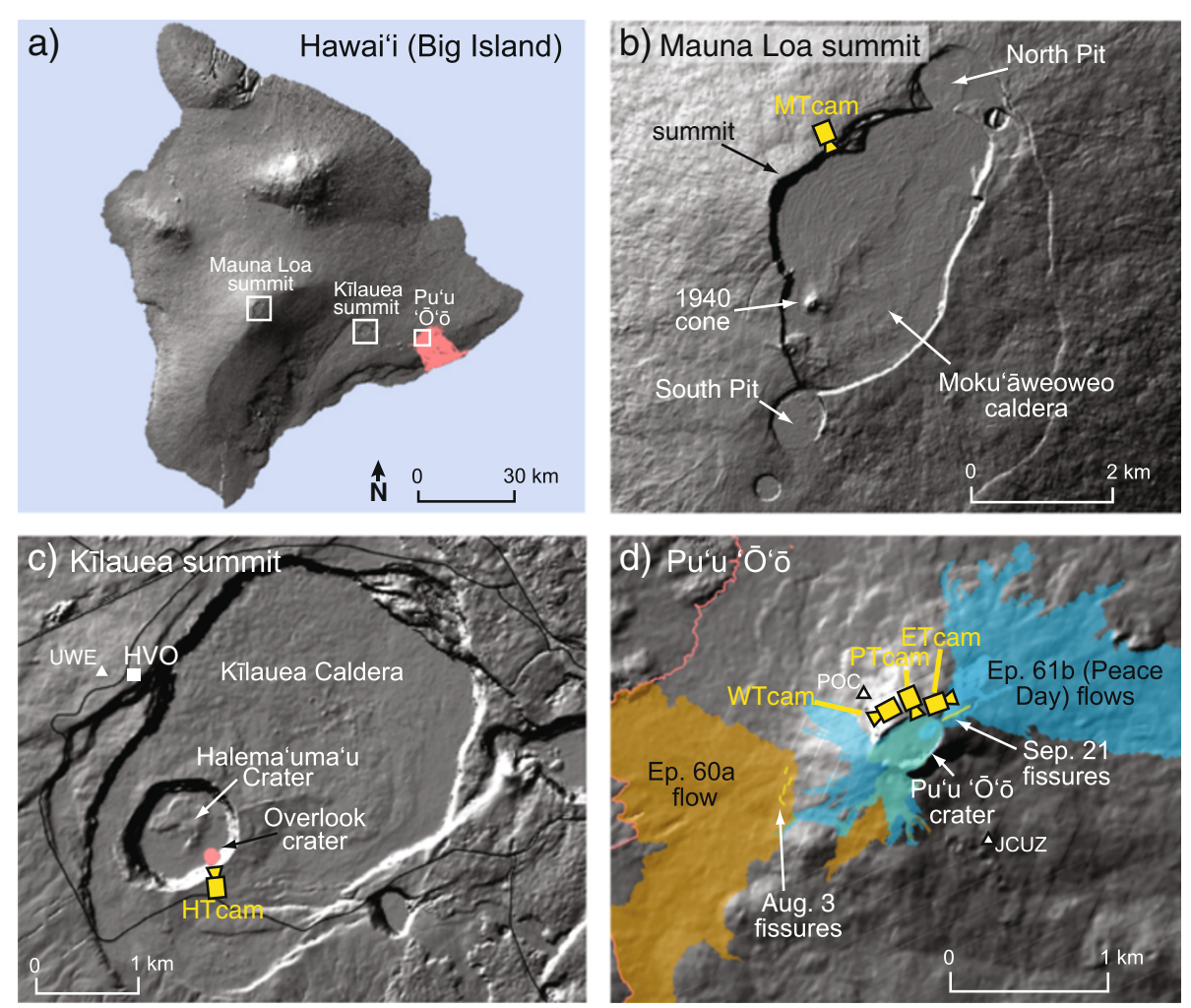

Figure 1 Location of thermal cameras on Killauea and Mauna Loa. a) Map of Hawai'i Island. Thermal cameras are deployed at the summit of Mauna Loa, the summit of Killauea and at the current vent area (Pu'u 'Ō'ö) along Kilauea's east rift zone. b) Moku'āweoweo caldera at the summit of Mauna Loa. The thermal camera is deployed along the north rim, pointed towards the center of the caldera and covering the majority of the caldera floor with its $75^{\circ}$ wide field of view. c) An active lava lake resides within the Overlook crater, within Halema'uma'u Crater in Kilauea's summit caldera. A thermal camera covers the majority of the Overlook crater in its field of view. The Hawaiian Volcano Observatory (HVO) and the UWE tiltmeter are 1.9-2.0 km from the lava lake. d) Pu'u 'O''o', the current vent area for the ongoing eruption on Kilauea's east rift zone, has had three thermal cameras. One views the eastern half of Pu'u 'Ō'ö crater, while the others have broad views east and west to monitor for nearby changes on the rift zone. POC is a tiltmeter on the north flank of the cone, while JCUZ is a GPS receiver south of the crater. The PUOC GPS receiver is not shown, but is very close to the location of the WTcam, on the north flank.

et al. 2007). During 2010-2012, deformation was minimal and earthquake activity was at background levels, giving no indication of imminent eruptive activity. Nevertheless, the time since Mauna Loa's last eruption stands as its longest historic repose period, based on data in Decker et al. (1995). Also, Mauna Loa's capacity for extremely higheffusion-rate flows $\left(500 \mathrm{~m}^{3} \mathrm{~s}^{-1}\right.$ or more, from Lipman and Banks (1987)) and high flow-advance rates requires close monitoring for potential signs of unrest. Fumarolic activity remains on the caldera floor (Casadevall and Hazlett 1983; Patrick and Witzke 2011).

\section{Camera limitations}

Although the cameras are intrinsically temperaturecalibrated, numerous extrinsic field conditions can result in the measured, or apparent, temperature being different than the actual surface temperature (Ball and Pinkerton 2006, Harris 2013, Additional file 2). The apparent temperature measured by the cameras will usually be lower than the actual surface temperature for several reasons. First, volcanic fume between the target surface and the camera will attenuate the radiant signal of the surface significantly (Sawyer and Burton 2006). In some cases, particularly if there is much condensed water in the plume, the target surface may be entirely blocked by fume. Second, an individual pixel temperature will be a composite of all the temperatures within the pixel footprint. If the hot target is small and the majority of the pixel area is cooler, this "mixed pixel" issue results in the pixel-integrated temperature being significantly lower than that of the hot target. The pixel footprint size therefore plays a part in the temperature accuracy-and effective sensitivity-of the cameras (Ball and Pinkerton 2006). This relates to another limitation of the cameras: thermal camera images tend to be very low resolution (Spampinato et al. 2011). The cameras used in this study have image sizes of $320 \times 240$ pixels (0.08 megapixels), which was the standard resolution available for this type of camera in 

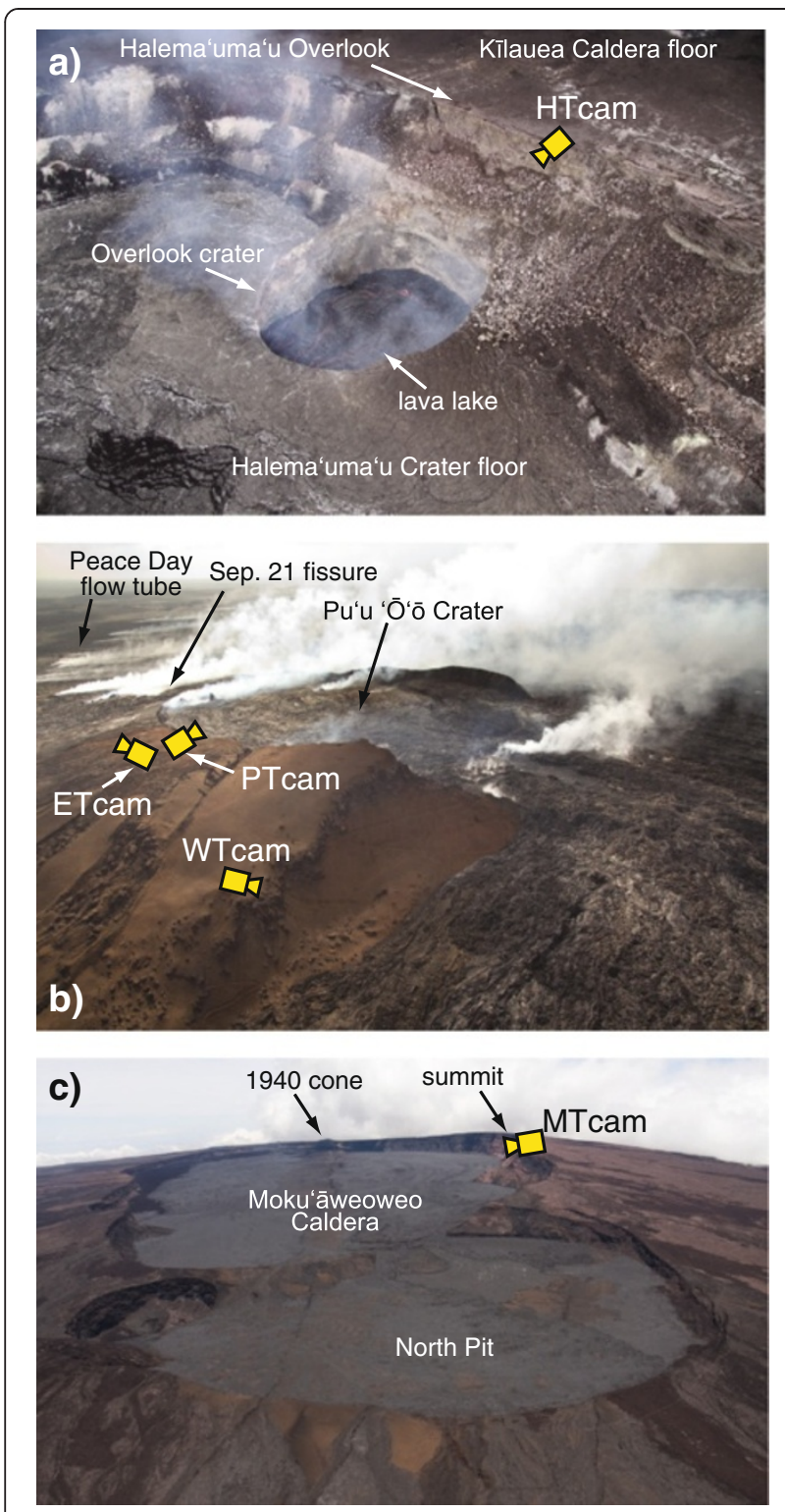

Figure 2 Aerial photographs of thermal camera deployment sites. a) At Kilauea's summit, a thermal camera (HTcam) is positioned on the rim of Halema'uma'u Crater, about $130 \mathrm{~m}$ above the active lava lake within the Overlook crater. Photo taken March 3, 2011. b) Thermal cameras are positioned on Pu'u 'Ō'ô to observe the activity within the crater (PTcam), as well as monitor changes east (ETcam) and west (WTcam) of the cone. Photo taken April 5, 2012, by Kyle Anderson (HVO). c) The MTcam is positioned along the north rim of Mauna Loa's summit caldera (Moku'āweoweo). Photo taken July 17, 2009, by Ben Gaddis (HVO).

2010. At a distance of $200 \mathrm{~m}$, the pixel footprint for the $53^{\circ}$ lens would be about $62 \mathrm{~cm}$ wide.

In some cases, the view of the target can be entirely blocked by volcanic fume. In Hawai' $i$, we have only seen this happen during phases when the plume is particleladen-for instance, immediately after a rockfall into the vent. These episodes are infrequent and last only seconds; the remainder of the time, the plume is always transparent in the infrared and observation is therefore essentially continuous. In other cases, such as in Alaska, volcanic fume often completely blocks the view of thermal cameras (Wessels et al. 2012). This may be due to the lower ambient temperatures, and higher abundance of condensed water droplets in those plumes.

Notwithstanding the above limitations in temperature accuracy, temperature-calibrated thermal cameras still provide more information than simple "relative" values, which could be provided by less expensive, uncalibrated, cameras. First, the temperature values are more intuitively useful for characterizing activity than the digital numbers output by uncalibrated cameras. Even with the above limitations in accuracy, they often still provide a good "ball park" temperature that is useful for basic hazard assessment, particularly for the casual user. Second, in most cases, the apparent temperature values will be an underestimate of the true surface temperature, and thus they can be taken as a minimum value that often has use. For instance, when observing an apparent temperature of $300^{\circ} \mathrm{C}$, we can assume the true temperature is higher than this, which in Hawai' is normally indicative of active, flowing lava. For the equivalent scenario with an uncalibrated camera, we might observe a digital number of 3420, which we take as a minimum value, but this has little use without much more context that may not be available to the casual user.

\section{Methods}

\section{Camera, enclosure and power}

The Mikron M7500L is a temperature-calibrated longwave $(7.5-13 \mu \mathrm{m})$ thermal camera that uses an uncooled microbolometer detector and produces an image with a size of $320 \times 240$ pixels (Table 1 ). Each image pixel depicts a unique temperature measurement in degrees kelvin. The camera, without additional lenses, is $18 \mathrm{~cm}$ long and about the size of a one-liter water bottle (Figure 3). The cameras measure temperatures over two different ranges (low: -40 to $120^{\circ} \mathrm{C}$; high: 0 to $500^{\circ} \mathrm{C}$ ). In this study, we mainly use the high range, because this covers both background temperatures (generally $10-40^{\circ} \mathrm{C}$ ) as well as temperatures on active lava surfaces (generally $>200^{\circ} \mathrm{C}$ ). The available lenses include the narrow-angle lens ( $11^{\circ}$ wide), root lens $\left(21^{\circ}\right)$, wide-angle spyglass lens $\left(53^{\circ}\right)$, and extreme wide-angle lens $\left(75^{\circ}\right)$. More details on the camera can be found in Additional file 1, and calibration information can be found in Additional file 2 .

The camera enclosure protects the camera from rain and corrosive gas and comprises several elements including the case, mounting plates, IR window and window frame. We used custom-made uncooled enclosures, following the basic design of by Harris et al. (2005) for radiometers, by Ripepe et al. (2009) and Lodato et al. (2009) 


\section{Table 1 Mikron M7500L camera specifications}

\begin{tabular}{|c|c|}
\hline Detector: & $\begin{array}{l}\text { Uncooled focal plane } \\
\text { array (microbolometer) }\end{array}$ \\
\hline Image size & $320 \times 240$ pixels \\
\hline Spectral range & 8-14 microns \\
\hline Instantaneous FOV: & $1.2 \mathrm{mrad}$ \\
\hline Image update rate: & $30 \mathrm{fps}$ \\
\hline Measurement accuracy: & $+/-2 \%$ or $2^{\circ} \mathrm{C}$ of reading \\
\hline Sensitivity/NE $\Delta T$ & $0.06^{\circ} \mathrm{C}$ at $30^{\circ} \mathrm{C}$ \\
\hline Measurement ranges: & Range 1: -40 to $120^{\circ} \mathrm{C}$ \\
\hline \multicolumn{2}{|l|}{ Range $2: 0$ to $500^{\circ} \mathrm{C}$} \\
\hline Digitization & 14 bit \\
\hline Interface & 100 Base T Ethernet \\
\hline Operating temperature: & -15 to $50^{\circ} \mathrm{C}$ \\
\hline Power supply: & $12 \vee D C$ \\
\hline Power consumption: & $10-13 \mathrm{~W}$ \\
\hline Dimensions (with root lens) & $8.2 \times 8.3 \times 17.9 \mathrm{~cm}$ \\
\hline Weight (with root lens) & $1.4 \mathrm{~kg}$ \\
\hline Available lenses: & Root: $21.7^{\circ} \times 16.4^{\circ}$ \\
\hline \multicolumn{2}{|c|}{ Spyglass: $53^{\circ} \times 40^{\circ}$ (lens is $16.3 \mathrm{~cm}$ long) } \\
\hline \multicolumn{2}{|c|}{ Extreme wide angle: $75^{\circ} \times 56^{\circ}$ (lens is about $8 \mathrm{~cm}$ long) } \\
\hline \multicolumn{2}{|c|}{$2 \times$ telephoto: $10.9^{\circ} \times 8.2^{\circ}$ (lens is $18.9 \mathrm{~cm}$ long) } \\
\hline
\end{tabular}

${ }^{*}$ This accuracy does not include extrinsic factors such as fume or the mixed pixel issue as described in text.

for thermal cameras at Stromboli and Vulcano, respectively, and by Orr and Hobblit (2008) for time-lapse cameras. Figure 3 shows the camera enclosures and field setup (see also Additional file 1). Table 2 has details on the major components.

In a lone configuration, the camera is powered by four 12-volt batteries which are recharged by two 80-Watt solar panels. Later upgrades to our instrument sites included large battery banks shared by multiple instruments. An IP-capable power relay unit was installed in order to remotely cycle the power (i.e., turn the camera off, then on) from the office. We found that the power relay unit was essential for reliable operation, as some camera problems could only be solved by cycling the camera power. Without the power relay unit, we would need to wait days or weeks until the next helicopter overflight to service the camera. Power consumption is described in Additional file 1.

\section{Telemetry and acquisition}

The camera outputs data through an Ethernet cable, which exits out the back of the enclosure and is run to a telemetry station that is generally a few tens of meters from the camera site. A WiFi radio at the telemetry station transmits the images back to the observatory in real-time. The telemetry station, which is powered by
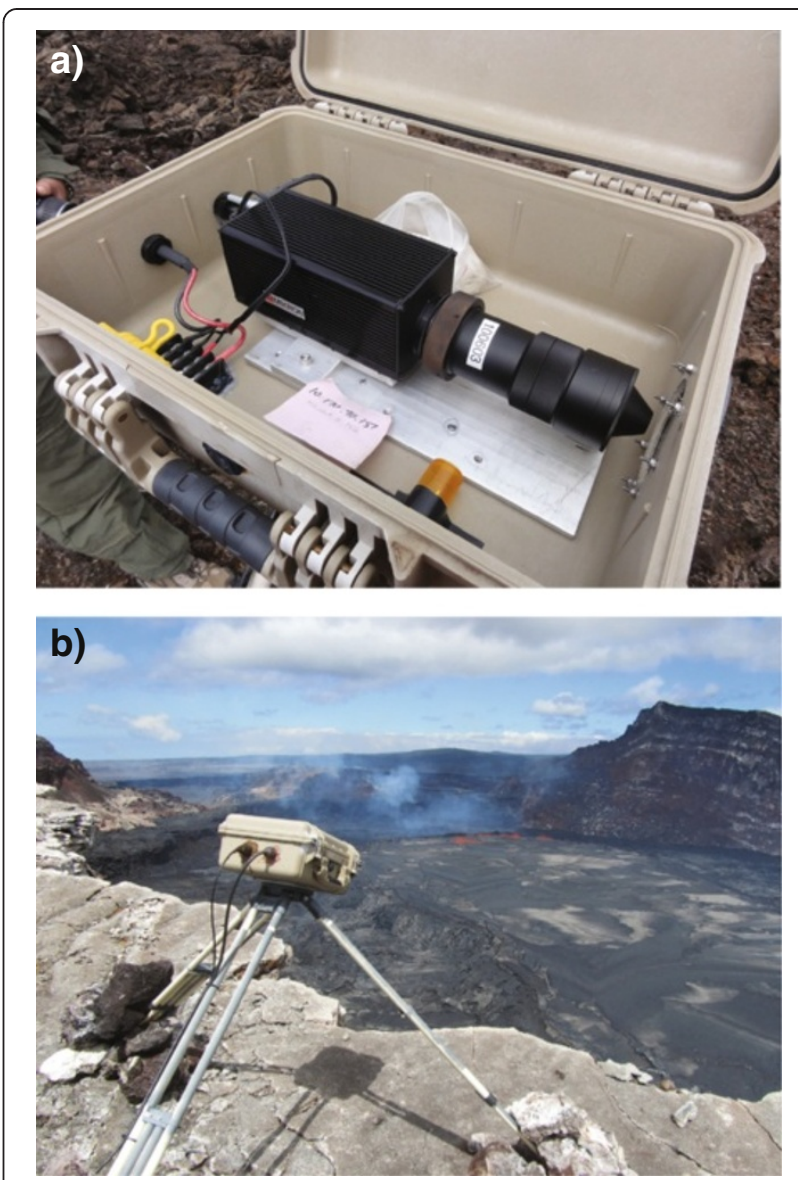

Figure 3 Thermal camera and field deployment. a) A Mikron $\mathrm{M} 7500 \mathrm{~L}$ thermal camera with a $53^{\circ}$ wide lens. The camera is protected by a custom-made enclosure made from a Pelican case. The camera looks through a germanium window attached to the front of the enclosure. b) Example deployment, showing the PTcam observing an active perched lava lake in Pu'u 'O'ōo crater in July 2011. Compare this view to Figure $9 \mathrm{~b}$.

its own batteries and solar panels or connected to a shared battery bank, may be used by several other instruments (e.g. GPS or other webcams) at the site.

We used two blade servers at the observatory to run the acquisition and processing. Details on the computer equipment are in Additional file 1.

\section{Deployment sites and acquisition schemes}

The first camera (HTcam) was installed at Halema uma $u$, viewing the lava lake, in October 2010 (Figures 1 and 2). Next, a thermal camera (PTcam) was installed at the rim of Pu'u 'O' ${ }^{\prime}$ o crater in March 2011 (Figures 1 and 2), just after the Kamoamoa eruption. This camera followed the repeated filling and draining of lava within the crater through the remainder of that year. In July 2011, anticipating possible breakouts on the flank of $\mathrm{Pu}^{\prime} \mathrm{u}$ ' $\mathrm{O}^{\prime}$ 'o cone, two cameras were installed on the upper flanks of the cone looking east (ETcam) and west (WTcam). A fifth 
Table 2 Equipment list and costs

\begin{tabular}{|c|c|c|c|}
\hline Item & Manufacturer & Quantity & Total cost \$USD \\
\hline \multicolumn{4}{|l|}{ Camera box } \\
\hline Mikron M7500L camera & Lumasense-Mikron & 1 & $15,600-16,900$ \\
\hline Germanium IR window (3" diam., $8 \mathrm{~mm}$ thick) & Novatech & 1 & 1500 \\
\hline PVC window frame (custom made) & AcTron Machine Co. & 1 & 100 \\
\hline Aluminum mounting plates (custom made set) & AcTron Machine Co. & 1 & 560 \\
\hline Surveyor's tripod & Dutch Hill & 1 & 325 \\
\hline Dessicant & & 1 & 3 \\
\hline Long ethernet cable & & 1 & 50 \\
\hline Miscellaneous electrical components & & & 15 \\
\hline \multicolumn{4}{|l|}{ Power supply } \\
\hline 12 volt car batteries (group 27105 Ah) & AC Delco & 4 & 360 \\
\hline $80 \mathrm{~W}$ solar panels & Sharp & 2 & 860 \\
\hline Charge controllers (10 amp) & Morningstar & 2 & 100 \\
\hline Power relay & ControlByWeb & 1 & 150 \\
\hline \multicolumn{4}{|l|}{ Telemetry } \\
\hline Wifi radio (CM9 radio card) & Avila & 1 & 400 \\
\hline Antenna (24 dB parabolic magnesium) & Commscope & 1 & 180 \\
\hline Network switch (model NS 205) & ICP DAS & 1 & 100 \\
\hline 12 volt car batteries (group 27105 Ah) & AC Delco & 4 & 360 \\
\hline $80 \mathrm{~W}$ solar panels & Sharp & 2 & 860 \\
\hline Charge controllers (10 amp) & Morningstar & 2 & 100 \\
\hline \multicolumn{4}{|l|}{ Software } \\
\hline Mikrospec RT-Multi and SDK & Lumasense-Mikron & & 8000 \\
\hline Matlab with image processing toolbox: & Mathworks & & 5000 \\
\hline PTFB software & Lighthouse & & 30 \\
\hline Total cost for one camera setup (excluding software): & & & $21,623-22,923$ \\
\hline
\end{tabular}

camera (MTcam) was deployed at the summit of Mauna Loa (Figures 1 and 2), overlooking the summit caldera, in October 2012.

We operated two types of acquisition: a high-rate version and low-rate version. The high-rate acquisition, which acquired an image every five seconds, was used only at Halema'uma'u (HTcam), where the highly dynamic and continuously circulating lava lake requires a high observation rate. The low-rate acquisition, in which images are acquired every few minutes, was used for all other cameras. This lower rate is adequate for most situations, given the typically slow rates of lava movement. These two acquisition schemes are detailed in the sections below.

\section{High-rate acquisition}

The high-frame-rate setup acquires an image every five seconds, though higher rates are possible. At this image rate, the total data rate is about $3.5 \mathrm{~Gb}$ per day. This setup uses the Mikron Mikrospec RT-Multi software to acquire images. Matlab scripts are run periodically in the background to ensure that the Mikrospec software is running, transfer the images to date-based folders, and perform additional analyses such as measuring lava level. The only camera to use this high-rate acquisition is the camera (HTcam) observing the highly dynamic lava lake in Halema'uma'u. Table 3 and Additional files 4 and 7 contain more details on the acquisition scripts.

Mikrospec RT-Multi (Version 2.10 build 209) is a program developed by Lumasense-Mikron to interface with their M7500 cameras and acquire and analyze images. We use it simply to acquire images and do not perform any analyses. The acquired images are written by the program to an acquisition directory, and Script $\mathrm{H} 2$ (Additional files 3 and 6) performs subsequent data management. Mikrospec maintains an open connection with the camera, even when not saving images, and consumes significant bandwidth. The software also sets the camera's non-uniformity correction (a periodic internal camera calibration) frequency, which we set to 15 minutes. 
Table 3 List of scripts

\begin{tabular}{|c|c|c|c|c|c|c|}
\hline $\begin{array}{l}\text { Script } \\
\text { number }\end{array}$ & Additional file & Script name & Description & Language & Run frequency & Run by \\
\hline \multicolumn{7}{|c|}{ High frequency acquisition (image every few seconds) for Mikron 7500 camera } \\
\hline $\mathrm{H} 1$ & 6 & checkmikrospec8.m & $\begin{array}{l}\text { Check to make sure Mikrospec RT } \\
\text { Multi is running }\end{array}$ & Matlab & Every 5 min. & WS $^{*}$ \\
\hline $\mathrm{H} 2$ & 6 & runprograms $3 . m$ & Run scripts H2a-d & Matlab & Every hour & WS \\
\hline $\mathrm{H} 2 \mathrm{a}$ & 6 & tempfilemove.m & $\begin{array}{l}\text { Move image files from local to } \\
\text { temporary directory for analysis }\end{array}$ & Matlab & Every hour & Script $\mathrm{H} 2$ \\
\hline $\mathrm{H} 2 \mathrm{~b}$ & 6 & lavalevelMikron_7run3.m & Measure lava level & Matlab & Every hour & Script $\mathrm{H} 2$ \\
\hline $\mathrm{H} 2 \mathrm{C}$ & 6 & crustvelocityMikron_test4.m & Measure crust velocity & Matlab & Every hour & Script $\mathrm{H}_{2}$ \\
\hline $\mathrm{H} 2 \mathrm{~d}$ & 6 & movelRfiles_mycomputer2.m & Archive images in date folders & Matlab & Every hour & Script $\mathrm{H}_{2}$ \\
\hline H3 & 6 & mikroncomposite2.m & Make composite image & Matlab & Every day & WS \\
\hline $\mathrm{H} 4$ & 6 & writevalvedata $2 . m$ & Write data to VALVE & Matlab & Every hour & WS \\
\hline $\mathrm{H} 5$ & 6 & freespacealert.m & Check hard drive space & Matlab & Once a day & WS \\
\hline \multicolumn{7}{|c|}{ Low frequency acquisition (image every few minutes) for Mikron 7500 camera } \\
\hline L1 & 7 & $\begin{array}{l}\text { AcquireMikronlmage_blade01. } \\
\text { m }\end{array}$ & $\begin{array}{l}\text { Acquire single image, make html } \\
\text { image, and archive }\end{array}$ & Matlab & Every $2-5$ minutes & WS \\
\hline L1b & 7 & MikronForm05.exe & $\begin{array}{l}\text { Connect to camera and acquire } \\
\text { single binary image }\end{array}$ & Visual BASIC .NET & Every $2-5$ minutes & Script L1 \\
\hline L2 & 7 & temperaturetrends 2 & Track temperature trends & Matlab & Every hour & WS \\
\hline L3 & 7 & temperaturealarmETWT.m & $\begin{array}{l}\text { Alarm if anomalous temperatures } \\
\text { detected }\end{array}$ & Matlab & Every 10 minutes & WS \\
\hline L4 & 7 & killmatlab.bat & Kill Matlab sessions that are hung & DOS & Once a day & WS \\
\hline L5 & 7 & mikroncomposite3.m & Make composite image & Matlab & Every day & WS \\
\hline L6 & 7 & pulsePTcam.m & $\begin{array}{l}\text { Cycle power on thermal camera } \\
\text { power relay }\end{array}$ & Matlab and HTML & Every week & WS \\
\hline L7 & 7 & checkacquisition.m & Send email if acquisition is failing & Matlab & Every hour & WS \\
\hline \multicolumn{7}{|c|}{ Low frequency acquisition (image every few minutes) for FLIR A320 camera } \\
\hline F1 & 4 & AcquireFLIRimage01.m & $\begin{array}{l}\text { Acquire single image, make html } \\
\text { image, and archive }\end{array}$ & Matlab & Every few minutes & WS \\
\hline
\end{tabular}

* Windows scheduler.

\section{Low-rate acquisition}

The low-frame-rate scheme is meant to acquire an image every few minutes. Unlike the high-rate acquisition Mikrospec program that maintains a continuous connection with the camera, this low rate approach only initiates a connection when an image is acquired, and immediately closes the connection, which minimizes bandwidth usage. For the image rates we use (an image every 2-5 minutes), the data rates are about $150 \mathrm{Mb}$ per day for each camera. This low-rate approach is largely contained within Script L1 (Additional files 3 and 7), and the other scripts perform accessory tasks, such as alarming and recording temperature trends. Table 3 and Additional files 3 and 7 contain more details on the acquisition scripts.

\section{Web display of images and data}

Image acquisition is only the first step in effective use of the thermal imagery. The images must be easily and immediately accessible to the entire observatory, and tools must be available to view sequences of images over recent time periods to provide a visual summary of ongoing activity. Once the thermal images are acquired on the acquisition computer, the JPEG images are immediately transferred to a browseable online image archive containing the most recent month of data. The current image and composite images (Patrick et al. 2010) are available as additional webpages (Figure 4). Automatically generated daily time-lapse movies are updated hourly and viewable on the website, and the last week of daily movies is available. These movies allow us to rapidly scan activity over the course of the day, making review of the images and detection of changes extremely time efficient. Time stamps in the individual images forming the movie allow comparison of changes in the images with other datasets, such as seismicity and deformation. This website is for internal use, but the public website (hvo.wr.usgs.gov) shows current webcam and thermal camera images.

In addition, our internal website has the web application VALVE (a time-series viewing interface, Cervelli et al. 


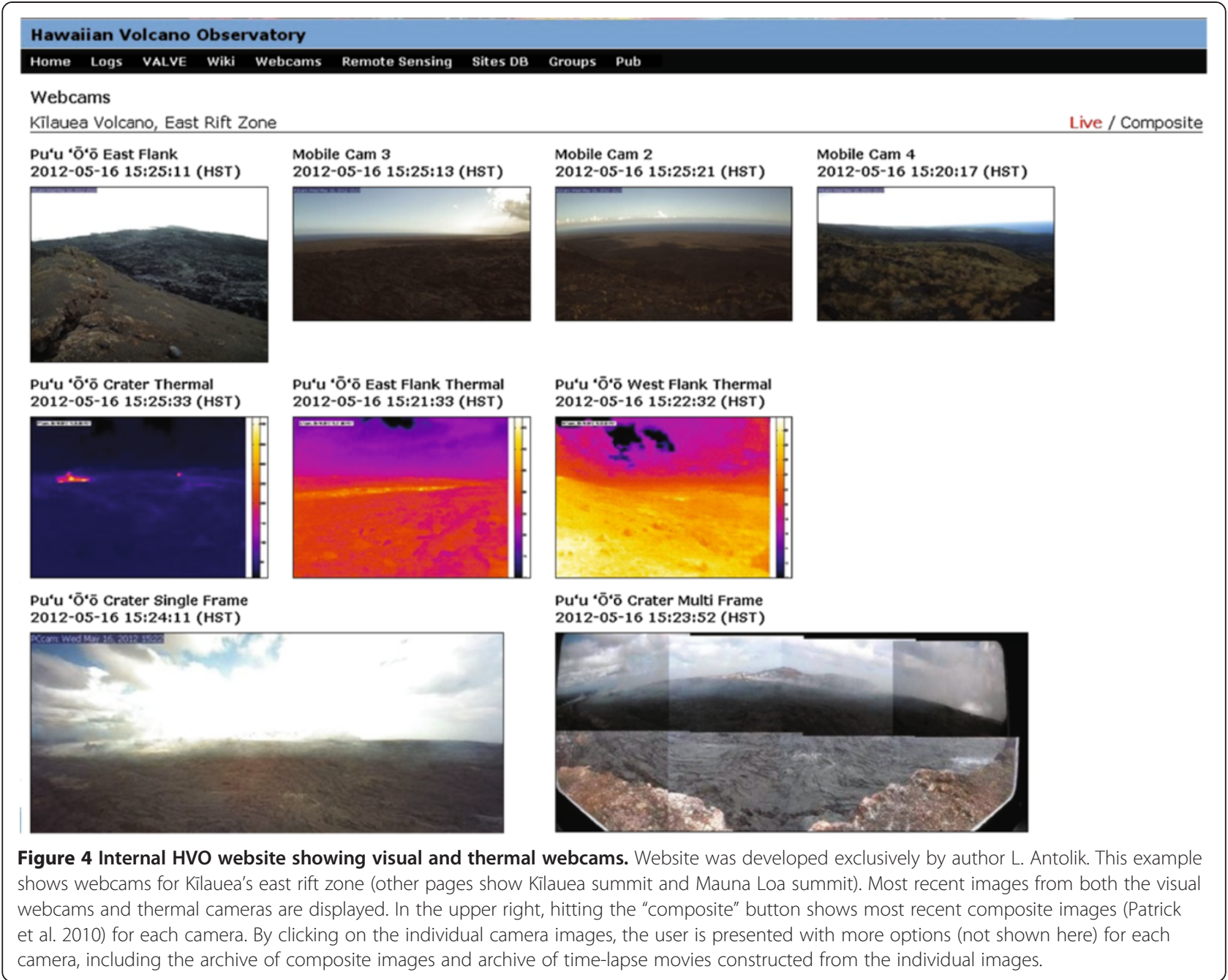

2002), and some products from the thermal cameras are shown using VALVE. For instance, the Halema'uma'u lava level (Script H2b, Table 3, Additional files 3 and 6) and the temperature trends in and around $\mathrm{Pu}^{\prime} \mathrm{u}{ }^{\prime} \mathrm{O}^{\prime}{ }^{\prime} \mathrm{o}$ (Script L2, Table 3, Additional files 3 and 7) are shown in VALVE.

\section{Performance}

The first months of setting up the cameras were challenging, with several computer issues that seemed to be related to operating system compatibility. Since these bugs were worked out and acquisition began, performance has been very good, with only brief interruptions. Details on performance issues and bugs are described in Additional file 5.

\section{Results and discussion Overall contribution}

The fixed thermal cameras in this study have provided a major improvement to monitoring at HVO. One of the primary benefits of the thermal cameras in Hawai'i is their ability to see through volcanic fume. The cameras have almost always been able to see through fume within Halema'uma'u Crater and $\mathrm{Pu}^{\prime} \mathrm{u}{ }^{\prime} \mathrm{OO}^{\prime}{ }^{\prime} \mathrm{o}$ crater, even when the view is completely obscured to the naked eye and to visual webcams (Figure 5). Essentially, the thermal cameras provide continuous observation that would not otherwise be possible. The images are served on the HVO public webpage (hvo.wr.usgs.gov/cams), and the clearer view of activity offered by the cameras therefore benefits both operational monitoring and public understanding of ongoing activity.

Another benefit is that thermal cameras provide a clearer and more consistent view of active lava flows than visible-wavelength webcams. Normal webcams may only show active lava flows clearly at night when incandescence stands out; during the day, lava may or may not exhibit obvious incandescence or color contrast with the surroundings, depending on activity levels and the nature of the surroundings. Thermal cameras, on the other hand, provide an unambiguous image of 


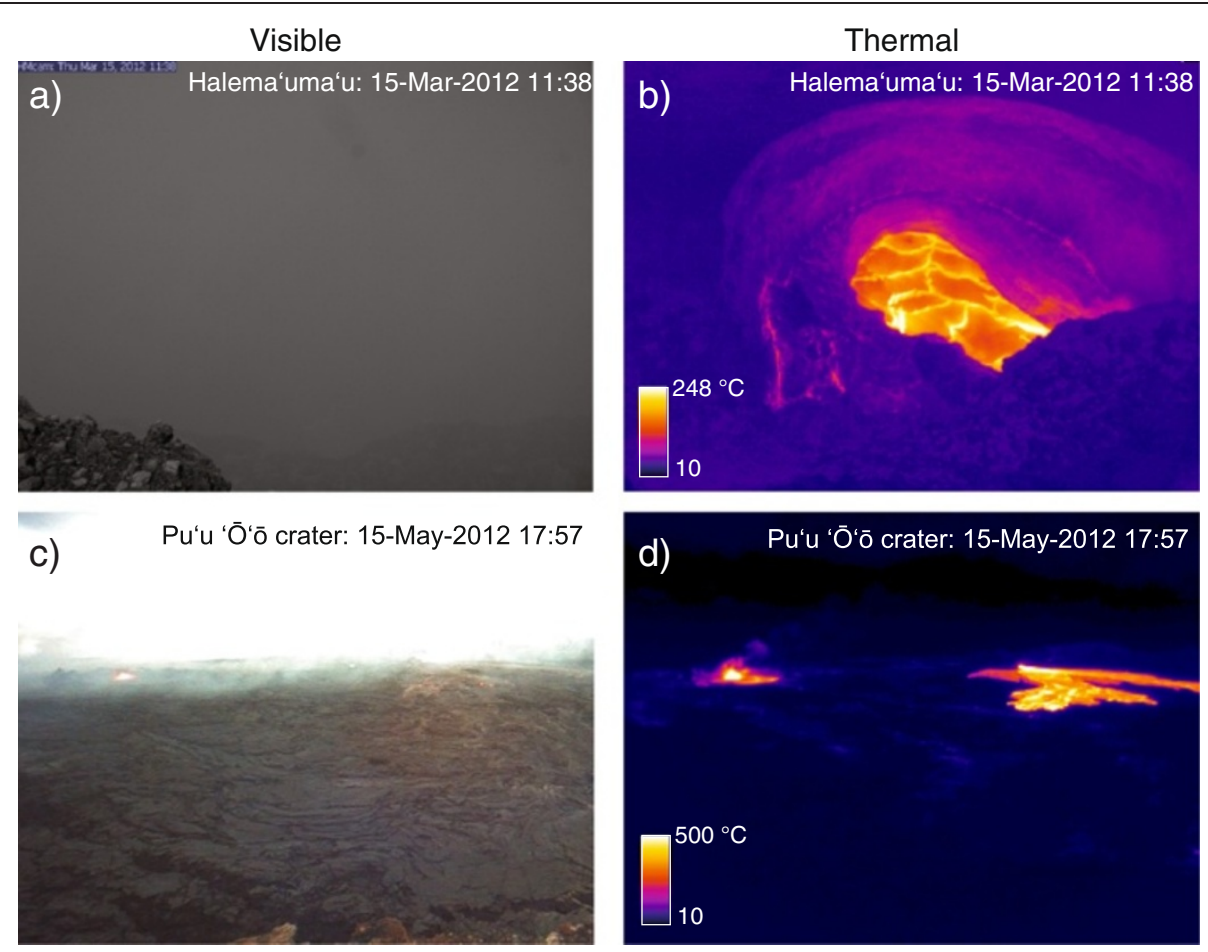

Figure 5 At Kilauea, thermal cameras can see through fume that obscures views to conventional webcams. Visible webcam (left) and thermal (right) images are shown for corresponding times, for Halema'uma'u (top) and Pu'u 'Ō'ó (bottom). For Halema'uma'u, note how the thermal camera (b) shows the active lava lake clearly even when the gas plume completely obscures the view to the visible webcam (a) and naked eye. For Pu'u 'O'Ō, note how the thermal camera (d) shows the extent of the small lava flow (right in image) and lava pond (left in image) very clearly, while the size and shape of these features are ambiguous in the visible webcam (c). The thermal images have not been corrected for atmospheric or volcanic gas effects, and actual surface temperatures may be higher than the apparent temperatures shown here.

flow activity, day or night (Figure 5). In addition, information on relative age of flow lobes can be roughly estimated by eye using the temperature information, in many instances.

Because thermal camera images are less sensitive to day-night fluctuations (the effects of solar heating are relatively minor for hot, active volcanic surfaces; see Additional file 2) and less susceptible to interference from fume, they provide a superior long-term view of activity compared to visible-wavelength webcams. Normal webcams will have daily changes in sunlight and illumination angle and variable visibility due to shifting fume, often making their long-term time-lapse sequences appear distractingly "busy" and therefore less informative. Longterm time-lapse sequences from the thermal cameras, in many cases, provide a substantially clearer view of evolving volcanic processes than time-lapse sequences from conventional webcams (see Additional files 8, 9, 10, 11, $12,13)$.

\section{Kïlauea summit: Automated lava-level tracking at Halema'uma'u}

Automated lava-level tracking (Script $\mathrm{H} 2 \mathrm{~b}$ in Table 3, Additional files 3 and 6) has been used at HVO to monitor the lava lake at Halema'uma'u. The script returns the lava level in units of image pixels, which is a relative measure but still useful for operational monitoring. Figure 6 has a sample time period, showing the automated lava level result compared with summit tilt. During this time period, the summit experienced several deflation-inflation (DI) cycles, which have been common since the start of the summit eruption (Poland et al. 2011). The lava level closely follows these tilt fluctuations, suggesting that the summit lava lake is a good pressure gauge for the summit magma reservoir.

\section{Kïlauea summit: Halema'uma'u long-term lava levels}

In 2011, the Halema'uma'u lava lake experienced dramatic changes in lava level, corresponding with changes in eruptive activity on the east rift zone (Figure 7; Additional file 8 ). The lava level was measured in the thermal camera images through most of 2011; continuous measurements were possible because of the thermal camera's unique ability to see through the thick fume in the vent. We converted the lava level in the thermal images, in pixels, to absolute elevation in meters using a linear best fit to sporadic laser rangefinder measurements of the lava level. 

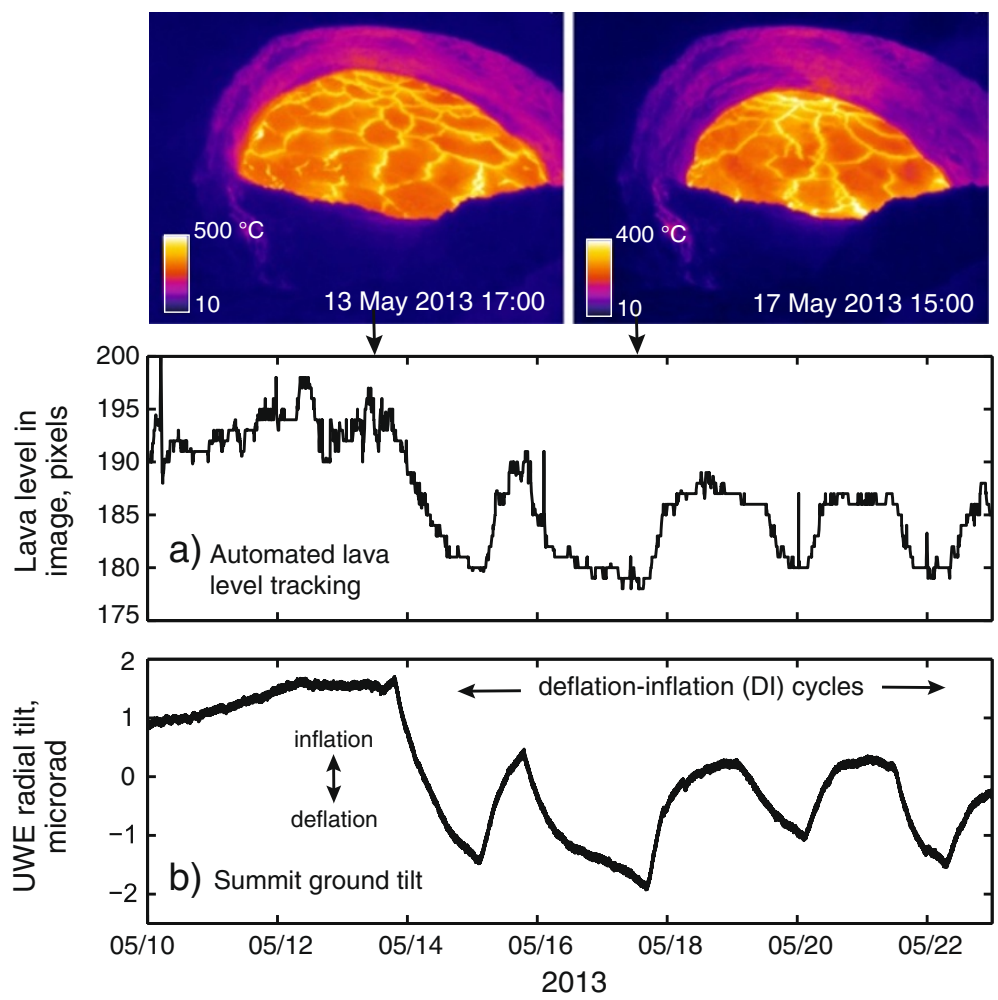

Figure 6 Automated lava lake level compared with summit tilt data. Lava level (a) is calculated from the HTcam thermal images (from Script $\mathrm{H} 2 \mathrm{~b}$ ). The summit frequently experiences deflation-inflation (DI) cycles as measured by ground tilt (b) (UWE tiltmeter location is shown in Figure 1c), and these fluctuations are closely followed by the summit lava lake level. This indicates that the summit lava lake acts as a liquid pressure gauge for the summit magma reservoir. The thermal images have not been corrected for atmospheric or volcanic gas effects, and actual surface temperatures may be higher than the apparent temperatures shown here.

In February 2011, the lava lake was at a relatively high level, following continued inflation of the summit. At its peak, the lava was about $62 \mathrm{~m}$ below the rim of the Overlook crater-the highest level for the eruption to that time. On March 5, increasing pressurization of the east rift zone conduit reached the failure point, and magma intruded from the conduit to the surface, triggering the Kamoamoa fissure eruption (Orr et al. 2013b). This depressurized the system and presumably diverted large amounts of magma from the east rift zone conduit, resulting in major lava level drops at both Halema'uma'u and $\mathrm{Pu}^{\prime} \mathrm{u}$ ' $\mathrm{O}^{\prime} \bar{o}$. Over the course of about 24 hours, the lava in Halema'uma'u dropped by about $140 \mathrm{~m}$. The lava largely disappeared from the vent for over a week, reappearing briefly as transient rises in lava level occurred due to summit deflation-inflation cycles. From March to August, the lava level rose at an unsteady rate during repressurization of the magmatic system. By early August it had nearly achieved its pre-Kamoamoa level, and was about $70 \mathrm{~m}$ below the vent rim. On August 3, fissures opened on the lower flank of $\mathrm{Pu}^{\prime} \mathrm{u}$ ' $\mathrm{O}^{\prime} \mathrm{o}$, again depressurizing the east rift zone conduit and leading to a rapid drop (of about $85 \mathrm{~m}$ ) in the Halema'uma'u lava lake. The level again recovered, and returned to relatively high levels by early September. On September 21, fissures again opened on $\mathrm{Pu}^{\prime} \mathrm{u}$ ' $\mathrm{O}^{\prime} \mathrm{o}$, and lava abruptly dropped a minor amount at Halema'uma'u.

Similar to Figure 6, Figure 7 shows a remarkable correlation between the lava-lake level in Halema'uma'u and the summit ground tilt. While Figure 6 demonstrates that the lava level acts as a reliable pressure gauge of the summit reservoir over a time-span of days, Figure 7 shows that this relation also applies over the course of weeks to months.

\section{Kîlauea summit: Halema'uma'u gas pistoning and lava lake circulation}

The lava lake in Halema'uma'u frequently undergoes cycles of "gas pistoning", which is a cyclic rise and fall of a lava surface that is commonly observed at Kilauea (Swanson et al. 1979; Patrick et al. 2011b; Orr and Rea 2012). Thermal-camera observations in late 2010 showed the lava lake in Halema'uma'u would slowly rise over the course of minutes to several tens of minutes as its surface migration velocity slowed, achieving a height of about $15 \mathrm{~m}$ above its background level. At this point, the lava 


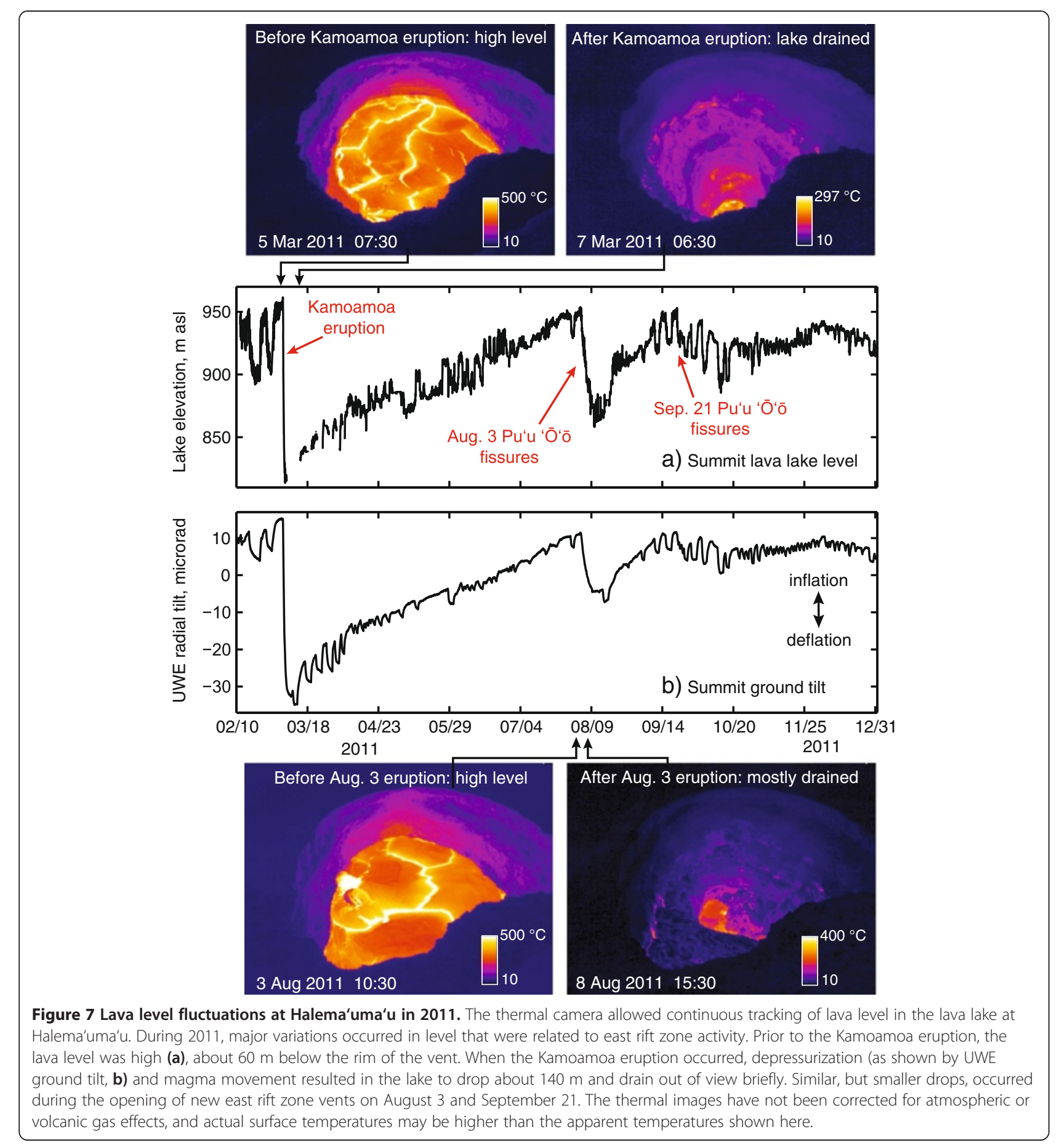

level could plateau for several hours, but eventually intense spattering would appear and the lava level would abruptly drop. The thermal camera at Halema'uma'u has captured hundreds of these events and provided some of the most detailed measurements of lava level and lava-lake surface velocity for gas piston events (Figure 8; Additional file 9).
Kīlauea east rift zone: Pu'u 'Ō'ō refilling and perched lava lake growth

Following the March 5-9, 2011, Kamoamoa eruption, lava reappeared in $\mathrm{Pu}^{\prime} \mathrm{u}$ 'Ō'o crater on March 26 and began to build a lava lake perched above its surroundings. The thermal camera captured the entire development of the perched lava lake, which likely comprises some of the 


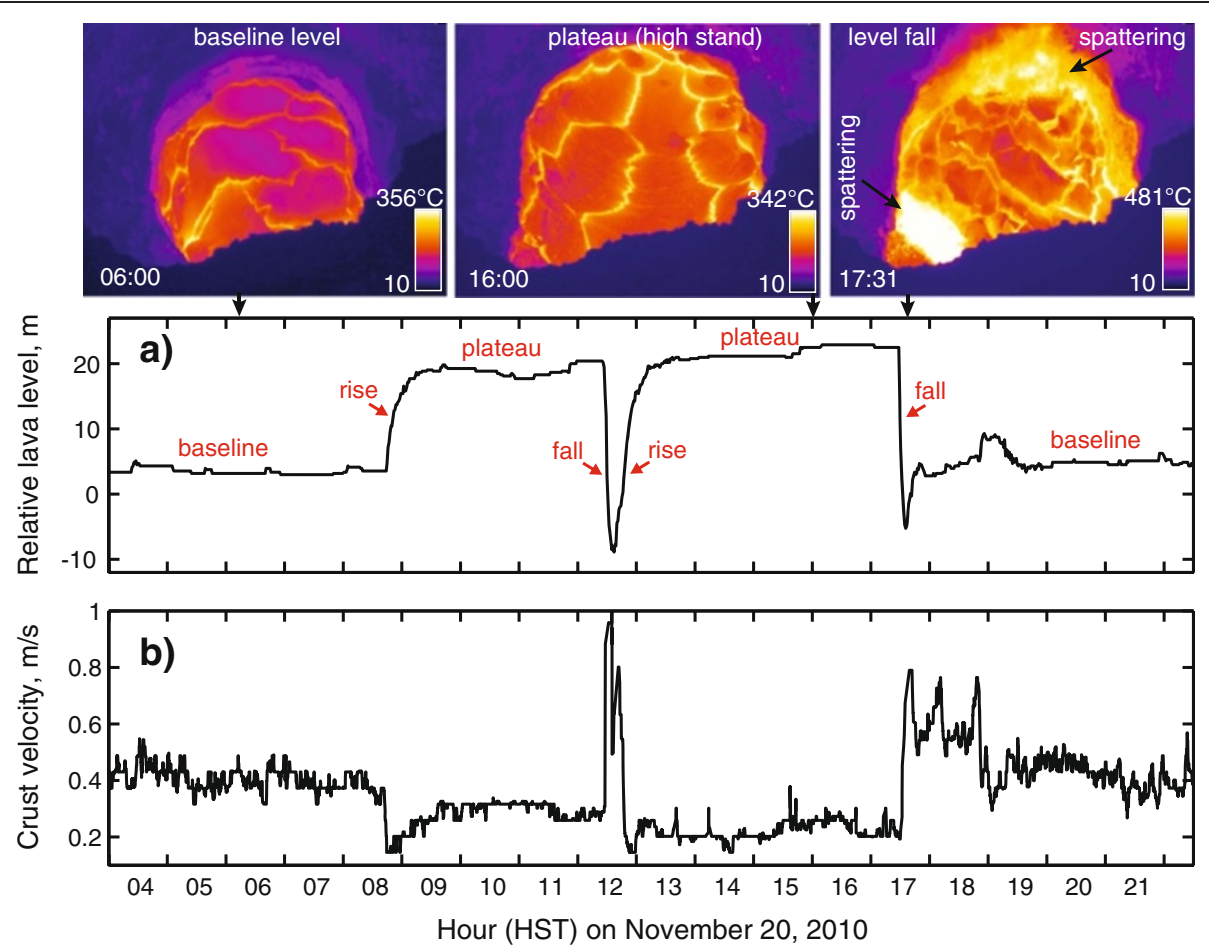

Figure 8 Gas pistoning in Kilauea's summit lava lake in Halema'uma'u Crater. a) Lava level on November 20, 2010, showing two episodes of gas pistoning, each lasting several hours long and involving the rise of the lava lake by about $15 \mathrm{~m}$. b) Approximate velocity of the surface crust on the lava lake for the same period. Gas piston events are often associated with a reduction in surface velocity. The thermal images have not been corrected for atmospheric or volcanic gas effects, and actual surface temperatures may be higher than the apparent temperatures shown here.

best observations of perched-lava-lake growth to date (Figure 9; Additional file 10). Between April and July, the perched lake rose substantially within $\mathrm{Pu}^{\prime} u$ ' $\bar{O}^{\prime} \mathrm{o}$ crater, approaching the crater rim (Figure 9a,b). The lake initially grew by lava spilling over the steep confining levees, building the levees further and buttressing their base with new flows. In July, we observed a remarkable new process. Portions of the lake flank were being uplifted in an endogenous manner (Figure 9c), suggesting that magma was being intruded at a shallow level below the lake. By late July, this was the main process of lake uplift and growth; flows rarely spilled over the levees. By the beginning of August, the lava level was approximately even with the east rim of $\mathrm{Pu}^{\prime} \mathrm{u}$ 'Ō'ō crater. On August 3, the lava within $\mathrm{Pu}^{\prime} \mathrm{u}$ ' $\overline{\mathrm{O}}^{\prime}$ ó abruptly drained (Additional file 11) through fissures on the lower west flank, disintegrating the lava lake (Figure 9d) as lava was erupted through the new fissures (Figure 10a-d). Presumably, this represented a relatively shallow failure of the $\mathrm{Pu}^{\prime} \mathrm{u}$ ' $\mathrm{O}^{\prime}$ ō edifice, in which magma was intruded through the flank of the cone due to increasing magmatic head pressure as lava level in the crater rose.
Killauea east rift zone: Onset of August 3 and September 21, 2011, fissure eruptions

The rapid draining of lava through the west flank of Pu'u 'Ō'o was captured by a thermal camera on the north flank of Pu'u 'O' ${ }^{\prime}$ ó (Figure 10a-d; Additional file 12). The thermal camera image was one of the first indications that a new fissure eruption had begun. It also documented the extremely high advance rate of the flows due to their unusually high effusion rate, which was presumably driven by the high magmatic head in the cone (akin to draining water from a bucket by punching a hole in its base). A preliminary estimate of the effusion rate from this fissure during the first 2.75 hours is $110-330 \mathrm{~m}^{3} \mathrm{~s}^{-1}$ DRE (dense rock equivalent), based on lava-flow-volume measurements. The draining mechanism and unusually high-effusion-rate flows are reminiscent of the 1977 flank eruption of Nyiragongo, DRC (Tazieff 1977).

The westward-viewing thermal camera also captured another intriguing process. The surface of the western flank of $\mathrm{Pu}^{\prime} \mathrm{u}$ ' $\mathrm{O}^{\prime}$ ó cone was observed to be briefly lifted immediately before the onset of the fissure eruption (Figure 10b; Additional file 12), presumably due to magma injection through this part of the cone. The WTcam 

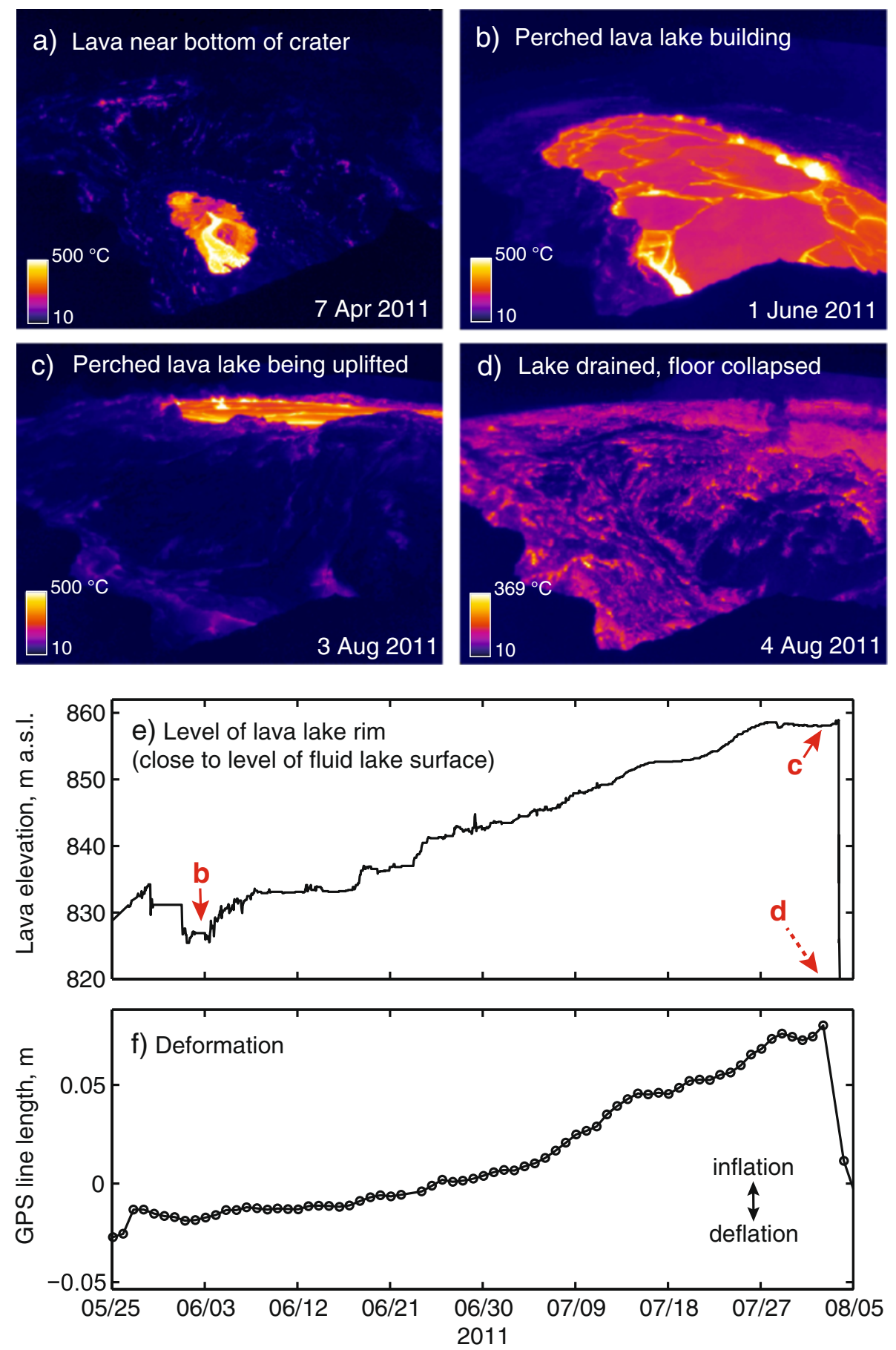

Figure 9 Lava level fluctuations at Pu'u 'Ō'ō in 2011. The thermal camera allowed continuous tracking of lava rise in Pu'u 'Ō'ō crater in mid-2011. Images are shown from the same camera (PTcam), which was not moved during this sequence. Following the draining of the crater during the Kamoamoa eruption in early March, lava began to refill the crater (a). By June a large (220 m long and $100 \mathrm{~m}$ wide) perched lava lake had formed, with steep levees (b) (corresponding visual image in Figure 3b). In July, endogenous uplift of the lake was common (c), pushing the lake level higher, almost to the level of the camera on the crater rim. On August 3, fissures opened on the lower west flank of the cone, draining the lava from the crater (d) and creating a large collapse depression about $80 \mathrm{~m}$ deep. The rising lava level (e) was mirrored by inflation (f), measured by the distance between GPS receivers (PUOC and JCUZ, Figure 1d) on opposite sides of the cone. The thermal images have not been corrected for atmospheric or volcanic gas effects, and actual surface temperatures may be higher than the apparent temperatures shown here. 

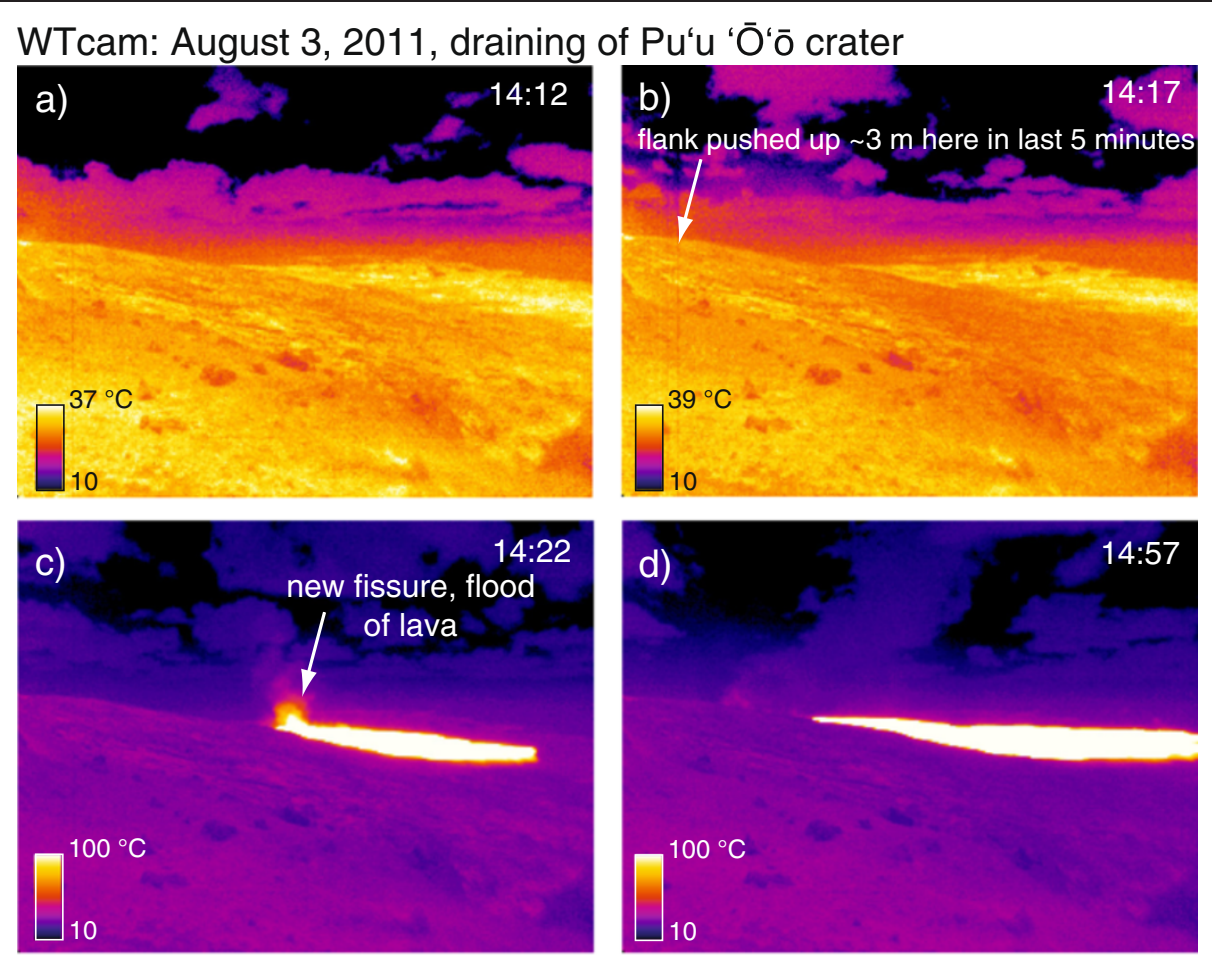

ETcam: Onset of September 21, 2011, fissure eruption
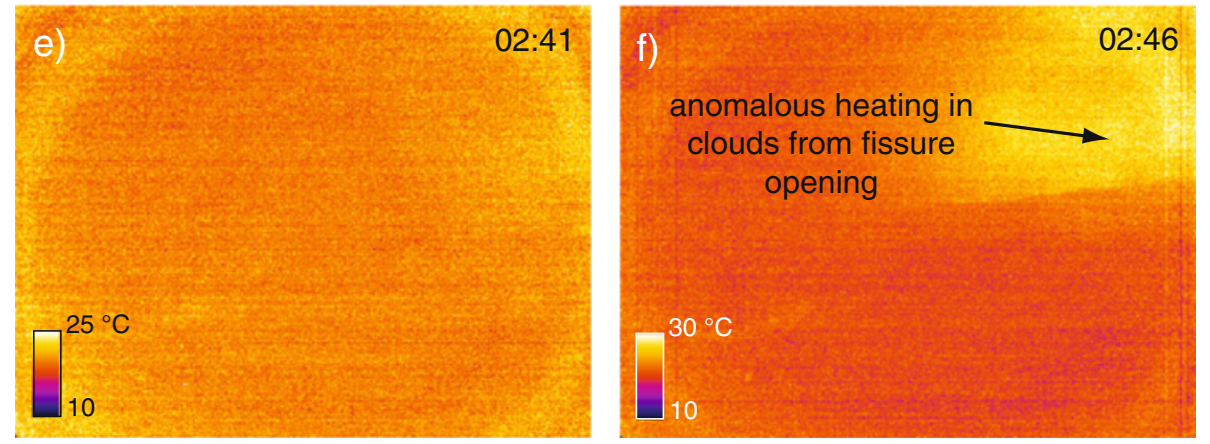

Figure 10 Detecting new fissure eruptions around Pu'u ' $\mathbf{O}^{\prime} \mathbf{o}$. On August 3, 2011, the WTcam observed the opening of new fissures on the lower west flank of $\mathrm{Pu}^{\prime} \mathrm{u} \mathbf{~} \mathrm{O}^{\prime} \mathrm{O}$, which drained the lava lake within the crater. Just minutes prior to the fissure opening, the camera captured the uplift of a portion of the west flank (a-b, about $3 \mathrm{~m}$ vertical movement in this image; $10 \mathrm{~m}$ uplift was observed elsewhere, out of this view, with other webcams). The uplift presumably resulted from a dike or sill propagating through the flank. Over a span of just four minutes, the surge of lava had traveled $600 \mathrm{~m}$ (c). The flow soon extended out of the field of view and entered the forest to the north (right side of image in $\mathbf{d}$ ). On September 21, 2011, a new fissure opened on the upper east flank of Pu'u 'Ō'ō cone. A direct view of the fissure was blocked by topography, but anomalous heating of the clouds and fog around the new vent was a clear indicator of the onset $(\mathbf{e}, \mathbf{f})$. The thermal images have not been corrected for atmospheric or volcanic gas effects, and actual surface temperatures may be higher than the apparent temperatures shown here.

thermal camera (Figure 2b) captured a portion of this deformation, which consisted of about $3 \mathrm{~m}$ of uplift of the surface. Another webcam on $\mathrm{Pu}^{\prime} u^{\prime}{ }^{\prime} \bar{O}^{\prime} \bar{o}$ showed that the portion of the cone that experienced the greatest deformation was uplifted $10 \mathrm{~m}$.

Following the August 3 draining, effusion was focused on the west flank of $\mathrm{Pu}^{\prime} \mathrm{u}$ ' $\mathrm{O}^{\prime}$ o for almost two weeks, but returned to $\mathrm{Pu}^{\prime} \mathrm{u}{ }^{\prime} \overline{\mathrm{O}}^{\prime}{ }^{\prime} \overline{\mathrm{o}}$ crater in late August. The crater once again began to fill with lava, and lava reached the rim again in mid-September. On September 13 at 17:50, the script that was running for the ETcam and WTcam detected the spillout of flows over the east rim, sending a text message alarm to cell phones belonging to HVO staff geologists T. Orr and M. Patrick. In the early morning of September 21, lava broke through a fissure just below the east rim of $\mathrm{Pu}^{\prime} \mathrm{u}^{\prime} \mathrm{O}^{\prime}$ 'o crater, sending flows towards the southeast. The fissure was just out of view of the ETcam, but elevated temperatures in the clouds and fog around the fissure indicated an increase in activity in that area (Figure 10e,f). 
Kīlauea east rift zone: Automated temperature tracking The cameras are very effective at quantitative tracking of surface activity, and particularly effusive events. We have found that a simple way of tracking effusive events is to plot the percentage of the image which is above some temperature threshold (Script L2, Table 3 and Additional files 3 and 7). Note that this is much more effective for this purpose than, say, tracking the average temperature in the image. Figure 11 and Additional file 13 show a sample period from late 2012, when a tiltmeter on the north flank of $\mathrm{Pu}^{\prime} \mathrm{u}$ ' $\mathrm{O}^{\prime}$ ō recorded sustained inflation around the cone. The inflation culminated in several effusive episodes, consisting of brief lava flows erupted onto the $\mathrm{Pu}^{\prime} \mathrm{u}$ ' $\mathrm{O}^{\prime}$ 'o crater floor, presumably due to increasing pressure in the shallow magmatic system. These temperature trends are analyzed hourly and automatically sent to the VALVE webserver for real-time tracking.

\section{Mauna Loa monitoring}

The 1984 eruption of Mauna Loa was reportedly preceded by thermal changes on the floor of the summit caldera (Lockwood et al. 1987). Thermal cameras may be effective at identifying thermal precursors to the next summit eruption, and would be very useful for tracking the progress of fissure development and fountaining at the summit. Currently, the thermal camera positioned at the north rim of the summit caldera shows stable fumarolic activity consistent with the spatial distribution mapped by Patrick and Witzke (2011) (Figure 12). This consists of several linear bands of high temperatures oriented northeast-southwest near the center of the

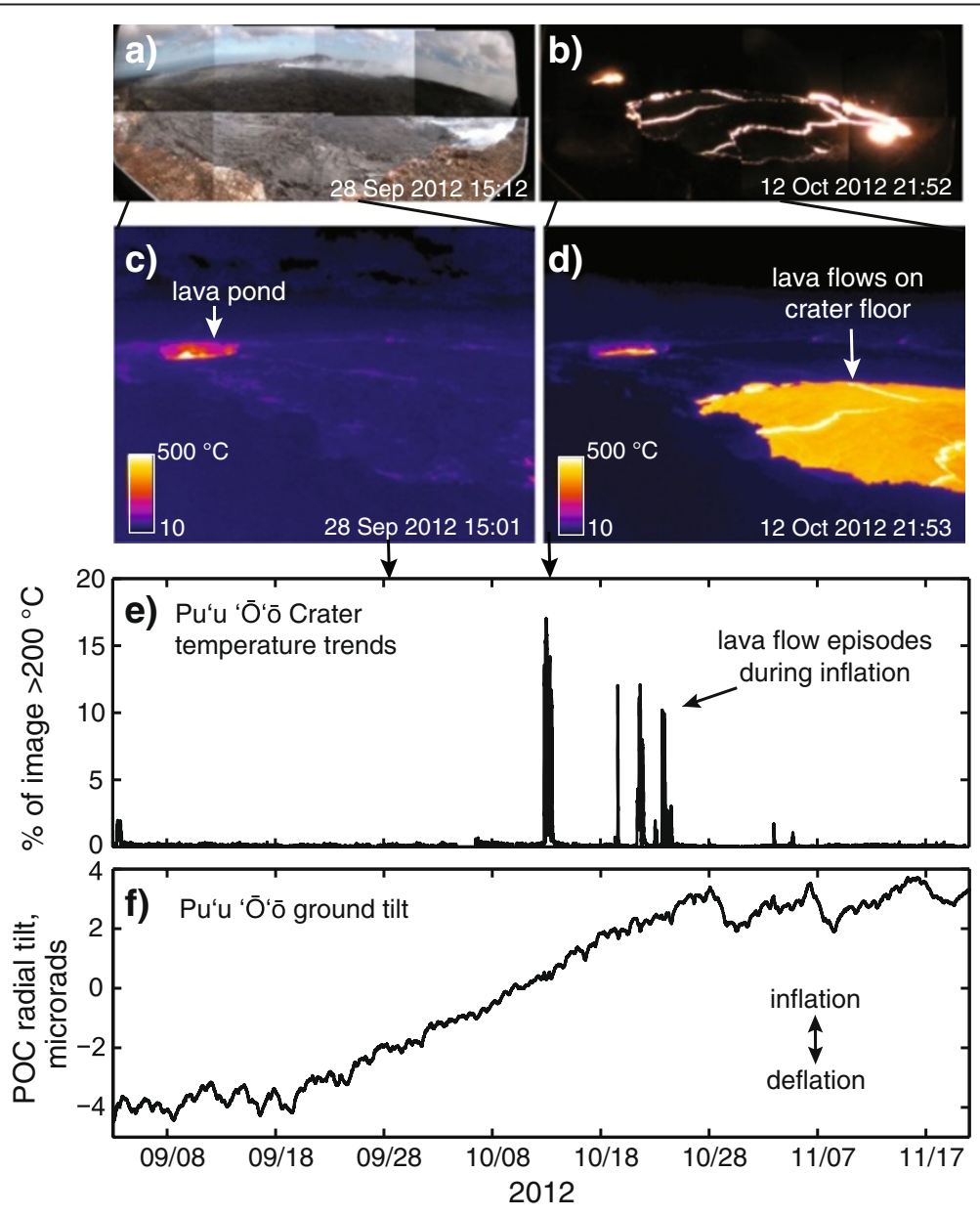

Figure 11 Tracking temperatures in real-time, and comparison with tilt data. In fall of 2012, inflation at Pu'u 'Ō'ō peaked in late October. As the cone inflated, several episodes of lava effusion onto the crater floor occurred, presumably due to increased pressure within the shallow magma reservoir. a-d) Corresponding visual webcam and thermal (PTcam) images at two times during this period. The thermal images cover only about the left half of the field of view of the visual images. e) Automated product from Script L2, showing the percentage of the PTcam image that is $>200^{\circ} \mathrm{C}$. This time series is very effective at highlighting effusive events. $\mathbf{f}$ ) Radial ground tilt from the POC tiltmeter (see Figure $1 \mathrm{~d}$ for tiltmeter location). The thermal images have not been corrected for atmospheric or volcanic gas effects, and actual surface temperatures may be higher than the apparent temperatures shown here. 

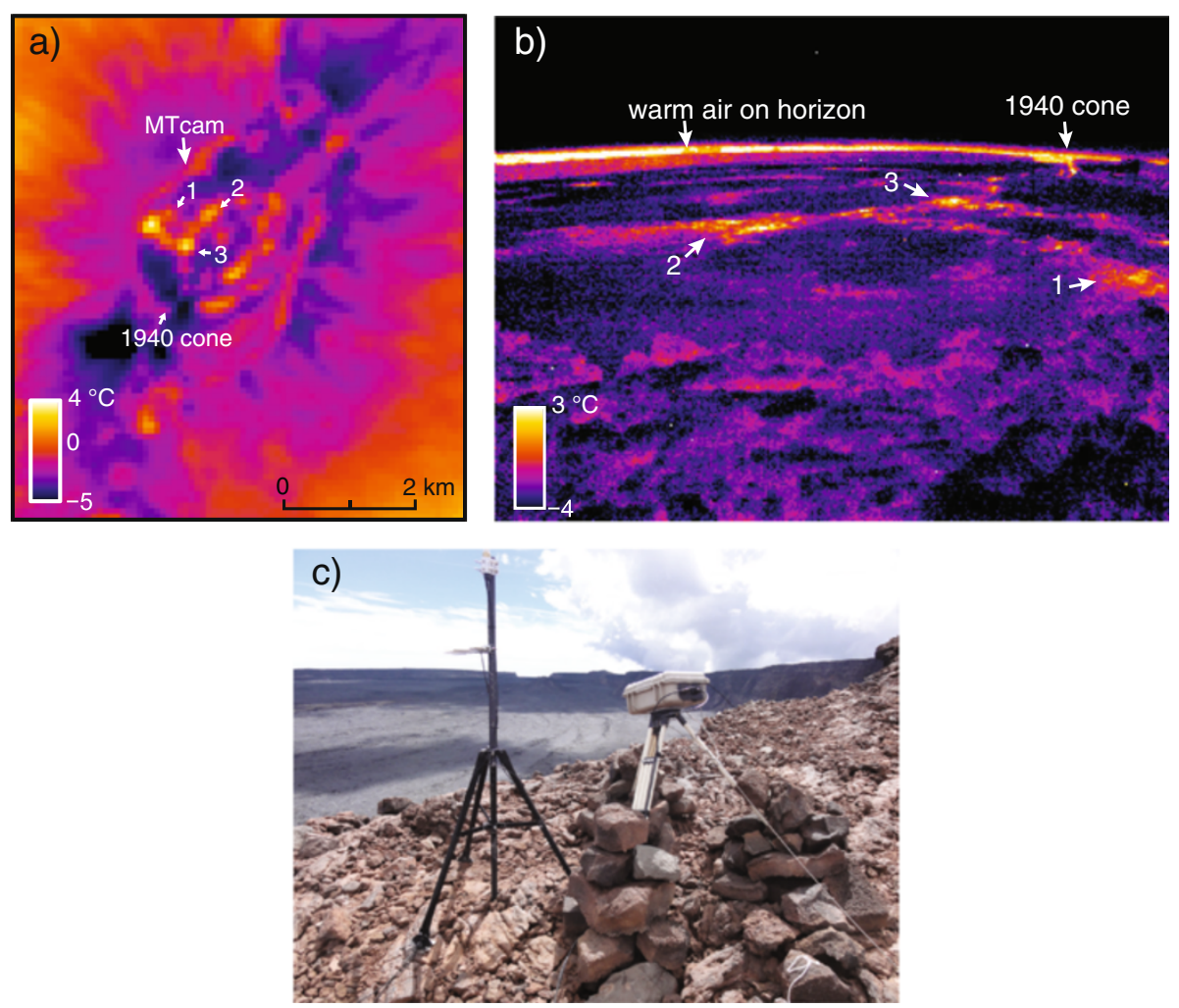

Figure 12 Monitoring Mauna Loa's summit caldera with a thermal camera. a) ASTER (Advanced Spaceborne Thermal Emission and Reflection Radiometer) satellite thermal image of Mauna Loa's summit, taken from Figure 12 in Patrick and Witzke (2011). Bands of elevated temperature correspond with fumarolic activity on the caldera floor. Numbered spots show corresponding areas visible in the MTcam image. b) Nighttime MTcam thermal camera image from the north rim showing the caldera (30 Nov 2013, 03:25 am). Distinct high temperature bands indicating fumarolic activity are easily visible at night (i.e. when solar heating is minimized). c) Photograph of the MTcam thermal camera (next to an unrelated antenna) looking out over the caldera floor. The thermal image has not been corrected for atmospheric effects, and actual surface temperatures may be higher than the apparent temperatures shown here.

caldera floor, intersecting two linear bands of high temperatures oriented northwest-southeast in the western portion of the caldera floor.

\section{Future work and improvement}

The cameras described in this setup have an image size of $320 \times 240$ pixels, which was the standard resolution for fixed thermal cameras during requisition in 2009. At that time, however, new cameras were appearing on the market with higher resolution. The FLIR SC655 camera has an image size of $640 \times 480$ pixels, which is four times the amount of data. At HVO, we have used handheld thermal cameras with both $320 \times 240$ and $640 \times 480$ image sizes and, while the $320 \times 240$ images provide a reasonably good image, the $640 \times 480$ images are remarkably sharper. As the price of these $640 \times 480$ cameras will hopefully decline in coming years, the next generation of the thermal camera setup described in this paper should incorporate one or more of the $640 \times 480$ cameras, or even higher-resolution cameras when they become available.
In our discussion of performance in Additional file 5, we describe how interfacing with the cameras was often tricky and fraught with difficulties, and troubleshooting problems related to operating system compatibility and other computer-related issues was one of the most timeconsuming parts of this project. New fixed thermal cameras appearing on the market may potentially reduce this problem by using a common, shared and open-source interface like GigE Vision and GenICam. The GenICam standard will essentially replace the proprietary software development kits (SDK) currently used, and hopefully make interfacing with the cameras less problematic.

A primary justification for purchasing the thermal cameras was their capability to automatically detect activity-that is, alarm-based on temperature changes. The alarming tool that we currently use (Script L3; Additional file 7) is very basic and uses a simple temperature threshold, but more sensitive techniques for detecting subtle changes are possible. For instance, the technique used by Pergola et al. (2004) and Koeppen et al. (2011) looks at long-term trends in thermal 
satellite images to build a picture of the normal variations in surface temperature at each pixel. This normal variation is constrained by a selected number of standard deviations around the long-term mean temperature for each pixel. The same approach could easily be applied to thermal camera images. When pixels start to deviate outside of their normal temperature envelope, the pixel is flagged and an alert is issued.

For thermal cameras looking out over broad areas, the precise location of alerted pixels is potentially useful for determining the geographical coordinates of, say, a new fissure. Currently at HVO, we use incandescence in nighttime images from our visual webcams to automatically locate active breakouts (Patrick et al. 2012b). By knowing the camera viewing geometry, the location of bright pixels in the images can be translated to azimuths from the camera. Mapping these azimuths as rays on a flow-field map then helps constrain the location of active breakouts. In some cases, we have mapped these pixel locations onto a DEM surface, providing absolute mapping of active breakouts. This same approach could easily be applied to the thermal camera images for automated mapping of anomalous thermal activity, and more sophisticated photogrammetric approaches might also have promise.

\section{Conclusions}

Thermal cameras have dramatically improved HVO's observational capabilities. The cameras have provided views of volcanic activity that would simply not have been possible with visible-wavelength cameras, enabling uninterrupted surface observations. They allow us to visually monitor the summit lava lake continuously, and identify and locate active lava flows day or night. Although costly, we deem thermal cameras a highly worthwhile investment.

\section{Additional files}

Additional file 1: Details on equipment and setup. This file contains
more information on the requisition of the equipment, details and
illustrations of the custom enclosures, description of the power and
telemetry systems, and illustrations of the field setups.

Additional file 2: Calibration information. This file contains details on the temperature calibration and other considerations for the cameras.

Additional file 3: Description of scripts. This contains brief descriptions of the scripts which run the high rate and low rate acquisition schemes.

Additional file 4: Acquisition script for FLIR A320. This file contains Matlab code which can be used to acquire images from the A320 thermal camera manufactured by FLIR Systems.

Additional file 5: Performance details. This file contains more information on performance issues, including initial problems in setting up the camera and small bugs.
Additional file 6: High rate acquisition scripts. This file contains Matlab code for the various scripts which run the high rate acquisition scheme.

Additional file 7: Low rate acquisition scripts. This file contains code, mostly in Matlab, to run the low rate acquisition scheme.

Additional file 8: Time-lapse video of Halema'uma'u lava lake fluctuations in 2011. This movie from the HTcam shows the fluctuating level of the lava lake in Halema'uma'u Crater during 2011, when several rift zone eruptive events disturbed the lake. The middle panel shows the elevation of the lava lake in the images. The lower panel shows distance between two GPS stations on either side of the summit caldera, with increasing values indicating inflation and decreasing values indicating deflation. For scale, the lake at its high point is about $150 \mathrm{~m}$ in diameter, and the total distance from high stand to low stand is about $140 \mathrm{~m}$.

\section{Additional file 9: Time-lapse video of gas pistoning in}

Halema'uma'u. This movie from the HTcam shows a selection of gas piston cycles at the lava lake in Halema'uma'u on January 16, 2011. The lake is about $75 \mathrm{~m}$ across in this image. Note that spattering, and visible gas emission, diminishes as the lava level rises, suggesting shallow gas accumulation.

Additional file 10: Time-lapse video of perched lava lake growth in Pu'u 'Ō'ō crater. This movie from the PTcam shows the development of a perched lava lake in Pu'u 'O'ó crater between April and August of 2011. Throughout July endogenous pressure caused significant uplift of the perched lake, steepening the levee walls. The lake drained on August 3 as fissures opened on the lower west flank of Pu'u 'Ō'ō cone. The lower panel shows distance between two GPS stations on either side of the crater, with increasing values indicating inflation and decreasing values indicating deflation. Note that the phase of endogenous uplift in July corresponds with an increased rate of inflation. For scale, the lake was about $200 \mathrm{~m}$ long, and its surface dropped roughly $80 \mathrm{~m}$.

Additional file 11: Time-lapse video of perched lava lake draining in Pu'u 'Ō'ó crater. This movie from the PTcam shows a detailed look at the draining of the perched lava lake in Pu'u 'Ö'ō on August 3, 2011. Note that the lake surface circulation is maintained throughout the early phases of the lake subsidence. The lower panel shows radial ground tilt from the nearby POC tiltmeter. Inflation precedes the lake collapse (presumably as magma moved laterally through the cone), with deflation accompanying the lake draining (presumably as magma drained out of the cone through west flank fissures). For scale, the lake is about $200 \mathrm{~m}$ long.

Additional file 12: Time-lapse video of the August 3, 2011, fissure opening at Pu'u 'Ō'ō crater. This movie from the WTcam shows an oblique view of fissures opening on the side of Pu'u 'Ō'ō cone on August 3, with draining of lava within Pu'u 'Ō'ō driving a massive flood of lava out of the fissures towards the west. As magma moved from within the cone towards the flank fissures, the west rim of the crater was briefly pushed up about $10 \mathrm{~m}$. This uplift is visible at the far left edge of the image, pushing the ground surface above the white dotted line, at the moment of peak inflation. Radial ground tilt from the nearby POC tiltmeter shows inflation preceding the breakout (presumably as magma moved laterally through the cone), with deflation accompanying the onset of fissuring (presumably due to magma draining out of the cone). For scale, the west rim portion that is uplifted is about $200 \mathrm{~m}$ from the camera, while the flows that erupt are about $1 \mathrm{~km}$ from the camera.

Additional file 13: Time-lapse video of lava flows in $\mathrm{Pu}^{\prime} \mathbf{u}^{\prime} \mathbf{O}^{\prime}$ ō crater in October 2012. This movie from the PTcam shows activity on the floor of Pu'u 'Ō'ō crater. During inflation in October 2012, several episodes of effusion fed lava flows on the crater floor. These flows were tracked with the automated temperature trend script. The middle panel shows radial ground tilt from the nearby POC tiltmeter. The lower panel shows results from that script, which shows the percentage of the image which is $>200^{\circ} \mathrm{C}$. The field of view of the camera is roughly $300 \mathrm{~m}$ wide.

\section{Competing interests}

The authors declare that they have no competing interests. 


\section{Authors' contributions}

MP requisitioned the cameras, wrote the code and the manuscript. TO and MP built the enclosures, determined camera locations and installed cameras in the field. LA developed the webserver and integrated the thermal camera feed, as well as configured VALVE for the thermal camera inputs. LL set up and maintained the acquisition computer system. KK performed electronics setup and maintenance. All authors read and approved the final manuscript.

\section{Acknowledgements}

Italian researchers were some of the earliest adopters of fixed thermal cameras on volcanoes, and this project was spurred in part by the demonstrated success of their systems. Specifically, Maurizio Ripepe (University of Florence) and Luigi Lodato (INGV-Catania) provided much helpful information on their fixed thermal camera setups on Stromboli and Vulcano, Italy. Andrew Harris provided additional helpful information, and Rick Wessels (AVO) provided advice and loaned us the FLIR A320 to test. Adolph Teves of AcTron Machine Co. worked closely with us to design the enclosure parts. Matt Ducharme and Kreg Kelley of Lumasense provided considerable assistance and answered many questions during initial camera setup. Bill Million and Cyril Moniz, both of HVO, have helped maintain the thermal cameras in the field. Comments from two anonymous reviewers were greatly appreciated. The use of manufacturer's names is provided for information only and does not constitute an endorsement by the US Geological Survey, the US Department of Interior or the US Government.

\section{Received: 2 August 2013 Accepted: 20 December 2013}

\section{Published: 21 Jan 2014}

\section{References}

Alparone S, Andronico D, Sgroi T, Ferrari F, Lodato L, Reitano D (2007) Alert system to mitigate tephra fallout hazards at Mt. Etna Volcano, Italy. Nat Hazards 43:333-350

Amelung F, Yun S-H, Walter TR, Segall P, Kim S-W (2007) Stress control of deep rift intrusion at Mauna Loa Volcano, Hawaii. Science 316:1026-1030

Arason P, Björnsson H, Petersen GN (2011) Plume-top altitudes during the Eyjafjallajokull 2010 eruption. EGU Geophys Res Abs 13:EGU2011-EGU7978

Ball M, Pinkerton H (2006) Factors affecting the accuracy of thermal imaging cameras in volcanology. J Geophys Res 111, B11203. doi:10.1029/ 2005JB003829

Behncke B, Falsaperla S, Pecora E (2009) Complex magma dynamics at Mount Etna revealed by seismic, thermal, and volcanological data. J Geophys Res 114, B03211. doi:10.1029/2008JB005882

Berk A, Anderson GP, Acharya PK, Bernstein LS, Muratov L, Lee J, Fox M Adler-Golden SM, Cetwynd JH, Hoke ML, Lockwood RB, Gardner JA, Cooley TW, Borel CC, Lewis PE, Shettle EP (2006) MODTRAN5: 2006 update. Proc SPIE 6233:62331F

Bonaccorso A, Calvari S, Garfi G, Lodato L, Patanè D (2003) Dynamics of the December 2002 flank failure and tsunami at Stromboli volcano inferred by volcanological and geophysical observations. Geophys Res Lett 30:1941-1944. doi:10.1029/2003GL017702

Bonaccorso A, Bonforte A, Calvari S, Del Negro C, Di Grazia G, Ganci G, Neri M, Vicari A, Boschi E (2011) The initial phases of the 2008-2009 Mount Etna eruption: A multidisciplinary approach for hazard assessment. J Geophys Res 116, B03203. doi:10.1029/2010JB007906

Calvari S, Lodato L, Steffke A, Cristaldi A, Harris AJL, Spampinato L, Boschi E (2010) The 2007 Stromboli eruption: event chronology and effusion rates using thermal infrared data. J Geophys Res 115, B04201. doi:10.1029/2009JB006478

Casadevall TJ, Hazlett RW (1983) Thermal areas on Kïlauea and Mauna Loa Volcanoes, Hawaii. J Volcanol Geotherm Res 16:173-188

Cervelli DP, Cervelli PF, Miklius A, Krug R, Lisowski M (2002) VALVE; volcano analysis and visualization environment. Eos Trans AGU 83(47). Fall Meet Suppl Abstract U52A-01

Chiodini G, Vilardo G, Augusti V, Granieri D, Caliro S, Minopoli C, Terranova C (2007) Thermal monitoring of hydrothermal activity by permanent infrared automatic stations: Results obtained at Solfatara di Pozzuoli, Campi Flegrei (Italy). J Geophys Res 112, B12206. doi:10.1029/2007JB005140

Decker RW, Klein FW, Okamura AT, Okubo PG (1995) Forecasting eruptions of Mauna Loa Volcano, Hawaii. In: Rhodes JM, Lockwood JP (ed) Mauna Loa Revealed: Structure, composition, history and hazards, Geophys Monogr vol 92. AGU, Washington, pp 337-348
Delle Donne D, Lacanna G, Marchetti E, Ripepe M, Ulivieri G (2006) Monitoring explosive volcanic activity using thermal images, Stromboli volcano, Italy. Eos Trans AGU 87(52). Fall Meet Suppl Abstract V43B-1795

Harris AJL (2013) Thermal remote sensing of active volcanoes: A user's manual. Cambridge Press, Cambridge

Harris A, Pirie D, Horton K, Garbeil H, Pilger E, Ramm H, Hoblitt R, Thornber C, Ripepe M, Marchetti E, Poggi P (2005) DUCKS: Low cost thermal monitoring units for near-vent deployment. J Volcanol Geotherm Res 143:335-360

Heliker C, Mattox TN (2003) The first two decades of the Pu'u 'Ō'o--Kupaianaha eruption: Chronology and selected bibliography. In: Heliker C, Swanson DA, Takahashi TJ (ed) The Pu'u 'O'ō-Kupaianaha eruption of Kïlauea Volcano, Hawai'i: The first 20 years. USGS Prof Paper 1676, pp 1-27

Hernández PA, Pérez NM, Varekamp JC, Henriquez B, Hernández A, Barrancos J, Padron E, Calvo D, Melian G (2007) Crater lake temperature changes of the 2005 eruption of Santa Ana Volcano, El Salvador, Central America. Pure App Geophys 164:2507-2522

Hoblitt RP, Orr TR, Castella F, Cervelli PF (2008) Remote-controlled pan, tilt, zoom cameras at Kïlauea and Mauna Loa volcanoes, Hawai'i. USGS Scientific Investigations Report 2008-5129

Kieffer HH, Frank D, Friedman JD (1981) Thermal infrared surveys at Mount St. Helens - observations prior to the eruption of May 18. In: Lipman PW, Mullineaux DR (ed) The 1980 eruptions of Mount St. Helens, Washington. USGS Professional Paper 1250, pp 257-278

Kirianov VY, Neal CA, Gordeev El, Miller TP (2002) The Kamchatkan Volcanic Eruption Response Team (KVERT). USGS Fact Sheet 064-02 [in English] and 151-02 [in Russian]

Koeppen WC, Pilger E, Wright R (2011) Time series analysis of infrared satellite data for detecting thermal anomalies: a hybrid approach. Bull Volcanol 73:577-593

Lipman PW, Banks NG (1987) Aa flow dynamics, Mauna Loa 1984. In: Decker RW, Wright TL, Stauffer PH (ed) Volcanism in Hawaii. USGS Professional Paper 1350, pp 1527-1568

Lockwood JP, Dvorak JJ, English TT, Koyanagi RY, Okamura AT, Summers ML, Tanigawa WR (1987) Mauna Loa 1974-1984: A decade of intrusive and extrusive activity. In: Decker RW, Wright TL, Stauffer PH (ed) Volcanism in Hawaii. USGS Professional Paper 1350, pp 537-570

Lodato L, Harris A, Drago L (2009) Thermal monitoring of Vulcano's fumarole field using a fixed automatic infrared thermal camera. Eos Trans AGU 90(52). Fall Meet Suppl Abstract V23D-2137

Miklius A, Cervelli P (2003) Vulcanology: interaction between Kïlauea and Mauna Loa. Nature 421:229

Miklius A, Cervelli P, Sako M, Lisowski M, Owen S, Segal P, Foster J, Kamibayashi K, Brooks B (2005) Global positioning system measurements on the Island of Hawai'i: 1997 through 2004. USGS Open-File Report 2005-1425

Moran SC, Freymueller JT, LaHusen RG, McGee KA, Poland MP, Power JA, Schmidt DA, Schneider DJ, Stephens G, Werner CA, White RA (2008) Instrumentation recommendations for volcano monitoring at U.S. volcanoes under the National Volcano Early Warning System. USGS Scientific Investigations Report 2008-5114

Oppenheimer C, Lomakina AS, Kyle PR, Kingsbury NG, Boichu M (2009) Pulsatory magma supply to a phonolite lava lake. Earth Planet Sci Lett 284:392-398

Orr TR, Hobblit RP (2008) A versatile time-lapse camera system developed by the Hawaiian Volcano Observatory for use at Kïlauea Volcano, Hawaii. USGS Scientific Investigations Report 2008-5117

Orr TR, Rea JC (2012) Time-lapse camera observations of gas piston activity at Pu'u 'O'o, Kilauea volcano, Hawai'i. Bull Volcanol 74:2353-2362. 10.1007/s00445-0120-0667-0

Orr TR, Thelen WA, Patrick MR, Swanson DA, Wilson DC (2013a) Explosive eruptions triggered by rockfalls at Kilauea Volcano, Hawaii. Geology 41:207-210

Orr TR, Heliker C, Patrick MR (2013b) The ongoing Pu'u 'O'o eruption of Kilauea Volcano, Hawai'i - 30 years of eruptive activity. USGS Fact Sheet 2012-3127

Patrick MR, Orr T (2011) Rootless shield and perched lava pond collapses at Killauea Volcano, Hawai'i. Bull Volcanol 74:67-78. doi:10.1007/s00445-011-0505-9

Patrick MR, Witzke CN (2011) Thermal mapping of Hawaiian volcanoes with ASTER satellite data. USGS Scientific Investigations Report 2011-5110

Patrick MR, Kauahikaua JP, Antolik L (2010) MATLAB tools for improved characterization and quantification of volcanic incandescence in Webcam imagery: applications at Kilauea volcano, Hawaii. USGS Techniques and Methods 13-A1 
Patrick MR, Orr T, Wilson D, Dow D, Freeman R (2011a) Cycles of spattering, seismic tremor and surface fluctuation within a perched lava channel, Kilauea Volcano. Bull Volcanol 73:639-653. doi:10.1007/s00445-010-0431-2

Patrick MR, Wilson D, Fee D, Orr T, Swanson D (2011b) Shallow degassing events as a trigger for very-long-period seismicity at Kilauea Volcano, Hawai'i. Bull Volcanol 73:1179-1186

Patrick MR, Orr T, Antolik L, Lee RC, Kamibayashi K (2012a) Continuous monitoring of Hawaiian volcanoes using thermal cameras. Abstract V41A2764 presented at Fall Meeting, AGU, San Francisco

Patrick MR, Orr T, Antolik L, Lee RC, Kamibayashi K (2012b) Recent improvements in monitoring Hawaiian volcanoes with webcams and thermal cameras. Abstract V33E-01 presented at Fall Meeting, AGU, San Francisco

Pergola N, Marchese F, Tramutoli V (2004) Automated detection of thermal features of active volcanoes by means of infrared AVHRR records. Rem Sens Environ 93:311-327

Poland MP, Dzurisin D, Lahusen RG, Major JJ, Lapcewich D, Endo ET, Gooding DJ, Schilling SP, Janda CG (2008a) Remote camera observations of lava dome growth at Mount St. Helens, Washington, October 2004 to February 2006. In: Sherrod DR, Scott WE, Stauffer PH (ed) A volcano rekindled: the renewed eruption of Mount St. Helens, 2004-2006. USGS Professional Paper 1750, pp 225-236

Poland MP, Miklius A, Orr T, Sutton J, Thornber C, Wilson D (2008b) New episodes of volcanism at Kilauea Volcano, Hawaii. Eos Trans AGU 89:37-38

Poland MP, Miklius A, Lundgren P, Sutton AJ (2011) Repeated deflation-inflation events at Kilauea, Hawaii: What's up (and down) with that? Abstract V51G-01 presented at Fall Meeting AGU, San Francisco, pp 5-9

Ripepe M, Delle Donne D, Lacanna G, Marchetti E, Ulivieri G (2009) The onset of the 2007 Stromboli effusive eruption recorded by an integrated geophysical network. J Volcanol Geotherm Res 182:131-136

Sawyer GM, Burton MR (2006) Effects of a volcanic plume on thermal imaging data. Geophys Res Lett 33, L14311. doi:10.1029/2005GL025320

Schaefer JR (ed) (2012) The 2009 eruption of Redoubt Volcano, Alaska, with contributions by Bull K, Cameron C, Coombs M, Diefenbach A, Lopez T, McNutt S, Neal C, Payne A, Power J, Schneider D, Scott W, Snediger S, Thompson G, Wallace K, Waythomas C, Webley P, Werner C. Alaska Division of Geological and Geophysical Surveys Report of Investigation 2011-5, 45 p. available at http://www.dggs.alaska.gov/pubs/id/23123

Sentman DD, McNutt SR, Stenbaek-Nielsen HC, Tytgat G, DeRoin N (2010) Imaging observations of thermal emissions from Augustine Volcano using a small astronomical camera. In: Power JA, Coombs ML, Freymueller JT (ed) The 2006 Eruption of Augustine Volcano, Alaska. USGS Prof Pap 1769, pp 569-577

Spampinato L, Calvari S, Oppenheimer C, Boschi E (2011) Volcano surveillance using infrared cameras. Earth-Sci Rev 106:63-91

Stevenson JA, Varley N (2008) Fumarole monitoring with a handheld infrared camera: Volcan de Colima, Mexico, 2006-2007. J Volcanol Geotherm Res 177:911-924

Swanson DA, Duffield WA, Jackson DB, Peterson DW (1979) Chronological narrative of the 1969-71 Mauna Ulu eruption of Kilauea volcano, Hawaii. USGS Prof Pap 1056

Tazieff H (1977) An exceptional eruption: Mt. Niragongo, Jan. 10th 1977. Bull Volcanol 40:189-200

Wessels RL, Vaughan RG, Patrick MR, Coombs ML (2012) High-resolution satellite and airborne thermal infrared imaging of precursory unrest and 2009 eruption at Redoubt Volcano, Alaska. J Volcanol Geotherm Res 259:248-269

Wilson D, Elias T, Orr T, Patrick M, Sutton AJ, Swanson D (2008) Small explosion from new vent at Kilauea's summit. EOS Trans AGU 89:203

Yokoo A (2009) Continuous thermal monitoring of the 2008 eruptions at Showa crater of Sakurajima volcano, Japan. Earth Planets Space 61:1345-1350

Yokoyama I (1964) Seismometrical observation of the 1962 eruption of Volcano Tokati, Hokkaido, Japan. Bull Volcanol 27:217-223

10.1186/2191-5040-3-1

Cite this article as: Patrick et al:: Continuous monitoring of Hawaiian volcanoes with thermal cameras. Journal of Applied Volcanology 2014, 3:1

\section{Submit your manuscript to a SpringerOpen ${ }^{\circ}$ journal and benefit from:}

- Convenient online submission

- Rigorous peer review

- Immediate publication on acceptance

- Open access: articles freely available online

- High visibility within the field

- Retaining the copyright to your article

Submit your next manuscript at $>$ springeropen.com 